\title{
Remote Sensing of Tillage Status
}

Baojuan Zheng

Arizona State University

James B. Campbell

Virginia Tech

Guy Serbin

Teagasc Food Research Centre

Craig S.T. Daughtry

USDA-ARS Hydrology and

Remote Sensing Laboratory

Heather McNairn

Agriculture and Agri-Food Canada

Anna Pacheco

Agriculture and Agri-Food Canada
Acronyms and Defin tions

179

8.1 Introduction

180

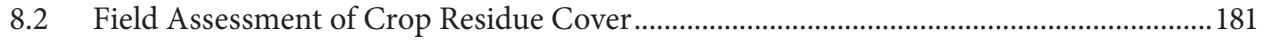

8.3 Monitoring with Optical Remote Sensing ....................................................................... 181

Spectral Properties of Soils, Green Vegetation, and Nonphotosynthetic Vegetation • Spectral

Indices for Assessing Crop Residue Cover • Tillage Assessment Using Airborne and Satellite Imagery • Summary

8.4 Monitoring with SAR

Introduction • Critical Variables for Tillage Assessment • Methods • Linking Radar

Products to Tillage Information - Summary

8.5 Review and Outlook.....

Challenges-Optical Systems • Challenges-SAR Systems • Challenges-Sequential

Observations • Challenges-Global Tillage Monitoring • Challenges-Field and

Validation Data

References..

\section{Acronyms and Definitions}

ALI

ALOS PALSAR

Advanced Land Imager

ASAR

ASTER

AVIRIS

CAI

CCD

COSMO-SkyMed

$\mathrm{CP}$

CTIC

DP

EnMAP

ERS

ESA

Hyperion

HyspIRI

IEM

Landsat-4, 5 TM

Landsat-7 ETM+
Advanced Land Observation Satellite Phased

Array type L-band Synthetic Aperture Radar

Advanced Synthetic Aperture Radar

Advanced Spaceborne Thermal Emission

and Reflection Radiometer

Airborne Visible/Infrared Imaging

Spectrometer

Cellulose absorption index

Coherent change detection

Constellation of Small Satellites for the

Mediterranean Basin Observation

Compact polarization

Conservation Technology Information Center

Dual polarization

Environmental Mapping and Analysis

Program

European Remote Sensing

European Space Agency

First spaceborne hyperspectral sensor

onboard Earth Observing-1(EO-1)

Hyperspectral Infrared Imager

Integral Equation Model

Thematic Mapper

Enhanced Thematic Mapper Plus
Landsat 8 OLI

LCA

LUT

minNDTI

MODIS

NDI

NDTI

NDVI

NIR

NPV

PolInSAR

PPD

QP

RISAT

RMS

SAOCOM

SARs

SINDRI

SMAP

SP

SPOT

STARFM
Operational Land Imager

Lignin cellulose absorption

Lookup table

Minimum NDTI

Moderate Imaging Spectroradiometer

Normalized difference index

Normalized difference tillage index

Normalized difference vegetation index

Near infrared

Nonphotosynthetic vegetation

Polarimetric interferometric

Copolarized phase difference

Quadrature polarization

Radar Imaging Satellite

Root mean square

SAtélite Argentino de Observación COn

Microondas; Argentine Microwaves

Observation Satellite

Synthetic aperture radars

Shortwave infrared normalized difference residue index

Soil Moisture Active Passive

Single polarization

Satellites Pour l'Observation de la Terre or Earth-observing satellites

Spatial and temporal adaptive reflectance fusion model 


$\begin{array}{ll}\text { STI } & \text { Simple tillage index } \\ \text { STIR } & \text { Soil Tillage Intensity Rating } \\ \text { SWIR } & \text { Shortwave infrared } \\ \text { TanDEM-X } & \text { TerraSAR-X add-on for Digital Elevation } \\ & \text { Measurement } \\ \text { VNIR } & \text { Visible, near-infrared } \\ \text { USDA } & \text { U.S. Department of Agriculture } \\ \text { USGS } & \text { U.S. Geological Survey }\end{array}$

\section{1 introduction}

Tillage prepares the seedbed by mechanical disturbance to loosen and smooth the soil surface, often mixing topsoil with surface organic debris to aerate soil, assist in weed suppression, control insects and pests, and, in midlatitudes, promote springtime warming and drying. Tillage has been practiced, in varied forms, throughout the world since antiquity. During the 1700 s and 1800 s, innovations in designs of plowshares greatly increased tillage eff ctiveness by increasing depth of the disturbed soil and by turning the surface soil to more completely mix surface crop residue (also referred to as plant litter, senescent vegetation, or nonphotosynthetic vegetation [NPV]) with disturbed soil.

For millennia, mechanical disturbance of the soil was accomplished using hand tools and animal power. By the mid-nineteenth century, steam-powered tractors (later replaced by internal combustion engines) greatly increased tillage efficiency and speed and expanded tillage into a wider range of slopes, topography, and ecosystems. Notable impacts of mechanization are the expansion of tillage into formerly uncultivated environments, especially prairies and steppes of several continents that have since become some of the most productive agricultural systems, but also some of the most susceptible to drought and erosion. Mechanization also led to further innovations in designs of specialized tillage implements and to increases in tillage operations, which often created the context for soil and water erosion.

Detrimental impacts of tillage include increased wind and water erosion; increased soil compaction, especially in the context of mechanization; decreased soil organic matter; reduced water infiltration; and increased amounts of nutrients reaching streams and rivers. By the 1940s, increased awareness of detrimental aspects of tillage (Faulkner 1943), combined with availability of herbicides, led to alternative practices to minimize adverse aspects of tillage. Such practices include increased use of tillage instruments that minimize soil disturbance and leave crop residue on the soil surface.

Recognized environmental benefits of conservation tillage systems include reduced soil erosion from wind and water, carbon emission reductions, and improvements of air, soil, and water quality (Wander and Drinkwater 2000). Long-term adoption of conservation tillage practices can increase soil organic matter content and, hence, can potentially sequester atmospheric carbon into soils (Lal 2004). Conservation tillage practices increase soil water infiltration, improve nutrient cycling, and, in general, improve water quality because of improved retention of soil nutrients (Karlen et al. 1994). Soil quality is improved because accumulation of surface organic matter increases aggregate stability and higher levels of crop residues provide shelter and food for wildlife. As for economic perspective, conservation tillage practices decrease labor and fuel costs because of reduced tillage operations and reduced fertilizer requirements as a result of improved soil quality (West and Marland 2002). Conservation tillage, especially no-till, requires fewer field operations and reduces the number of field days needed to plant a crop. As a result, it reduces the risk of delayed planting due to unfavorable weather conditions and also provides possibilities to practice double-cropping.

As alternative tillage practices gained acceptance and were implemented, conservationists needed objective data to gauge the extent and benefits of their use. The Soil Tillage Intensity Rating (STIR), developed by USDA-Natural Resource Conservation Services (NRCS), provides a physically based evaluation of tillage systems across the spectrum from true no-till to conventional plow systems (USDA-NRCS 2014). STIR requires information on (1) each tillage implement used, (2) the operating speed of the implement, (3) the depth of tillage, and (4) the fraction of the total soil surface disturbed by the tillage implement. STIR provides robust evaluations of complex tillage systems and crop rotations for conservation planning. However, STIR is impractical for surveys over many fi lds and large regions.

Tillage intensity can also be characterized by the fraction of the soil surface covered by crop residue. The Conservation Technology Information Center (CTIC) defined the following categories of tillage based on the crop residue cover on the soil surface shortly after planting: conventional tillage has $<15 \%$ residue cover, reduced tillage has $15 \%-30 \%$ residue cover, and conservation tillage has $>30 \%$ residue cover (CTIC 2014). This less robust definition of tillage intensity has a few caveats that must be considered, for example, fields where crop residues were harvested for feed or biofuel may have low crop residue cover without soil-disturbing tillage.

Over time, varied efforts to collect information on tillage intensity have included visual assessment, field measurements, agricultural censuses, and remote-sensing techniques. Such information is required by a number of agroecosystem models and is important for assessing the impacts of tillage practices on soil erosion, soil carbon sequestration, and water quality. Field measurements and agricultural surveys to acquire tillage information are time-consuming and difficult. Moreover, it is unrealistic to survey every single field using these methods over large regions and over time. Therefore, it is of great interest to develop techniques that can routinely and systematically map tillage practices. Synoptic remote-sensing imagery offers opportunities to provide spatial-temporal information on tillage practices efficiently at low costs. The first investigation on the potential of using remote-sensing imagery to map crop residues can be traced back to Gausman et al. (1975). Thereafter, both aerial and satellite imagery were tested to differentiate different tillage practices and estimate crop residue cover. For instance, Airborne Visible/ Infrared Imaging Spectrometer (AVIRIS) data were found to be useful for crop residue cover estimation (Daughtry et al. 2005).

Although aerial imagery, properly timed and collected at suitable resolutions, offers the capability to assess soil tillage status, 
the broadscale surveys require the areal coverage, revisit capabilities, and spectral channels that are, as a practical matter, available only through satellite observation systems. Here we discuss the two main classes of satellite systems with the potential for routine broadscale tillage assessment: (1) optical remote sensing (visible, near-infrared [NIR], and midinfrared imaging sensors) and (2) microwave remote sensing (synthetic aperture radar [SAR]).

\subsection{Field Assessment of c rop Residue c over}

Methods appropriate for assessing crop residue cover in fields can be grouped into intercept and photographic techniques (Morrison et al. 1993). Intercept methods use a system of grid points, crosshairs, or points along a line where the presence or absence of residue is determined. The standard technique used by USDA-NRCS is the line-point transect method where a 15-30 m line with 100 evenly spaced markers along the line is stretched diagonally across the crop rows in the field and markers intersecting crop residue are counted. Accuracy of the line-point transect method depends on the length of the line, the number of points per line, and the skill of the observer. At least 500 points must be observed to determine corn residue cover to within $15 \%$ of the mean (Laflen et al. 1981). Significant modifications to the line-point transect method include the use of measuring tapes, meter sticks, and wheels with pointers (Corak et al. 1993; Morrison et al. 1993). However, the line-point transect is impractical for monitoring crop residue cover in many fields over broad areas in a timely manner.

For the photographic method, a color or color infrared digital camera is used to take multiple vertical photographs within a sampling area where residue conditions appear visually homogeneous. A grid or crosshairs is superimposed on the digital images and the points intersecting residue are counted. Software programs, such as SamplePoint, can randomly select sample points within each image for the user to identify and can tabulate the proportion of each class (Booth et al. 2006). Alternatively, the image may be classified into soil and residue classes using objective image analysis procedures. Classification errors occur when the spectral differences between soil and residues classes are not sufficiently large for discrimination. Shortly after harvest, crop residues are often much brighter than soils, but as the residues decompose, the residues may be brighter or darker than the soil. The best time to acquire information of tillage practices in the field is shortly after sowing and before crop emergence, which is also the optimal time window to acquire images to map tillage practices.

The CTIC, established at Purdue University in 1983 as clearinghouse for tillage and conservation information, has conducted fi ld surveys to assess tillage status in the United States (http:// www.ctic.purdue.edu). For the CTIC surveys, trained observers visually assessed tillage status in fi lds at regular intervals along selected routes through participating counties. The survey provided county-level estimates of overall tillage practices. The roadside assessment task is subject to various degrees of error and uncertainty because it mainly relies on visual interpretation.
TABLe 8.1 Tillage Types and Their Corresponding Crop Residue Cover

\begin{tabular}{|c|c|c|c|}
\hline Tillage Category & Tillage Types & Description & $\begin{array}{l}\text { Crop Residue } \\
\text { Cover }(\%)\end{array}$ \\
\hline \multirow[t]{3}{*}{ Conservation } & $\begin{array}{l}\text { No-till/ } \\
\text { strip-till }\end{array}$ & $\begin{array}{l}\text { Minimal soil } \\
\text { disturbance }(<25 \%)\end{array}$ & $\begin{array}{l}>30 \text { (likely } \\
>70)\end{array}$ \\
\hline & Ridge till & $\begin{array}{l}\text { Residue left } \mathrm{n} \text { the } \\
\text { surface between } \\
\text { ridges }\end{array}$ & $>30$ \\
\hline & Mulch till & $\begin{array}{l}\text { 100\% Soil surface } \\
\text { disturbance }\end{array}$ & $>30$ \\
\hline \multirow[t]{2}{*}{ Nonconservation } & Reduced till & $15 \%-30 \%$ & $15-30$ \\
\hline & $\begin{array}{l}\text { Conventional } \\
\text { till or } \\
\text { intensive till }\end{array}$ & $<15 \%$ & $<15$ \\
\hline
\end{tabular}

The quality of the data has also varied from time to time and from county to county due to a variety of reasons, such as unfavorable weather conditions at the time of survey and inconsistent levels of experience among the observers. Finally, some counties have stopped acquiring tillage data after the national survey program was discontinued in 2004 (CTIC 2014).

Limited soil tillage information is available for other countries. Canada conducts tillage inventory as part of its 5-year census of agriculture. Tillage practices are reported by province in three categories: (1) tillage incorporating most of the crop residue into the soil, (2) tillage retaining most of the crop residue on the surface, and (3) no-till seeding or zero-till seeding. Thus, it is difficult and impractical to evaluate tillage practices over time, and by nation, because of wide variations in field data collection, survey responses, and agricultural censuses (Zheng et al. 2014). The tillage categories defined by Canada are less precise than the CTIC definitions. Definitions of tillage categories may slightly differ from one country to another and even differ from organization to organization. To evaluate tillage practices for a particular field using visual assessment or remote-sensing methodologies, we have to link the ground surface status observed from the ground, air, or space to types of tillage practices. Although soil texture and smoothness can be one of the indicators for different tillage status, the amount of crop residues left on the ground after planting are often considered as the most reliable indicator. Here, we list types of tillage practices and their expected crop residue cover according to CTIC and NRCS's definitions in Table 8.1. Globally, a systematic monitoring of soil tillage is needed to manage the finite soil resources as demand for food, feed, fiber, and fuel intensifies.

\subsection{Monitoring with o ptical Remote Sensing}

Optical remote-sensing imagery is valuable for monitoring biophysical properties of various objects on the Earth. Crop residue, although spectrally similar to soils, has a unique absorption feature near $2100 \mathrm{~nm}$. The absorption depth becomes deeper as the amount of crop residue increases. Thus, optical remote-sensing imagery provides a better capability for estimating crop residue 
cover than does radar data. This section firstly describes spectral properties of soils, green vegetation, and NPV, following with Section 8.3.2 on tillage spectral indices based on spectral differences among soils, green vegetations, and NPV. Section 8.3.3 reviews tillage assessment using different remote-sensing platforms, followed by Section 8.3.4, which discusses current challenges and future possibilities.

\subsubsection{Spectral Properties of Soils, Green Vegetation, and n onphotosynthetic Vegetation}

Soil tillage intensity is defined by the proportion of the soil surface covered by crop residue shortly after planting. Green vegetation may also be present in the field as the planted crop or as weeds. This section focuses on the spectral properties of soils, green vegetation, and crop residues.

\subsubsection{Spectral Properties of Soils}

Soil reflectance typically increases monotonically with increasing wavelength (Figure 8.1). Major contributors to the reflectance spectra of soils include moisture content, iron oxide content, organic matter content, particle-size distribution, mineralogy, and soil structure (Baumgardner et al. 1986; Ben-Dor 2002). Stoner and Baumgardner (1981) measured the spectral reflectance of 485 soil samples representing 10 soil taxonomic orders and identified 5 distinct soil reflectance curve forms. Soil organic matter content and iron oxide content were the primary factors determining shape of the reflectance spectra.

In general, soil reflectance decreases as soil moisture content, organic matter content, and iron oxide content increase. Spectral reflectance is strongly correlated with soil organic matter among soils from the same parent materials (Henderson et al. 1992). Reflectance spectra of soils may also have absorption features near $2210 \mathrm{~nm}$ that are associated with $\mathrm{Al}-\mathrm{OH}$ in phyllosilicate clays (Figures 8.1 and 8.2) (Serbin et al. 2009b). However, mineral absorption features evident in the reflectance spectra of dry soils are often obscured by the strong absorption of water in the reflectance spectra of wet soils (Stoner et al. 1980; Daughtry et al. 2004).

Soil tillage roughens the soil surface and often decreases soil reflectance, but the effect is short-lived and soil reflectance increases as the soil surface is smoothed by precipitation or additional tillage operations (Irons et al. 1989). As water wets the soil surface and fills pore spaces, soil reflectance decreases.

\subsubsection{Spectral Properties of Green Vegetation}

Reflectance of solar radiation from a dense canopy of actively growing green plants is characterized by three distinct regions: visible, NIR, and shortwave infrared (SWIR) (Figure 8.1). In the visible wavelength region (400-700 $\mathrm{nm}$ ), chlorophyll and other leaf pigments strongly absorb blue and red wavelengths,

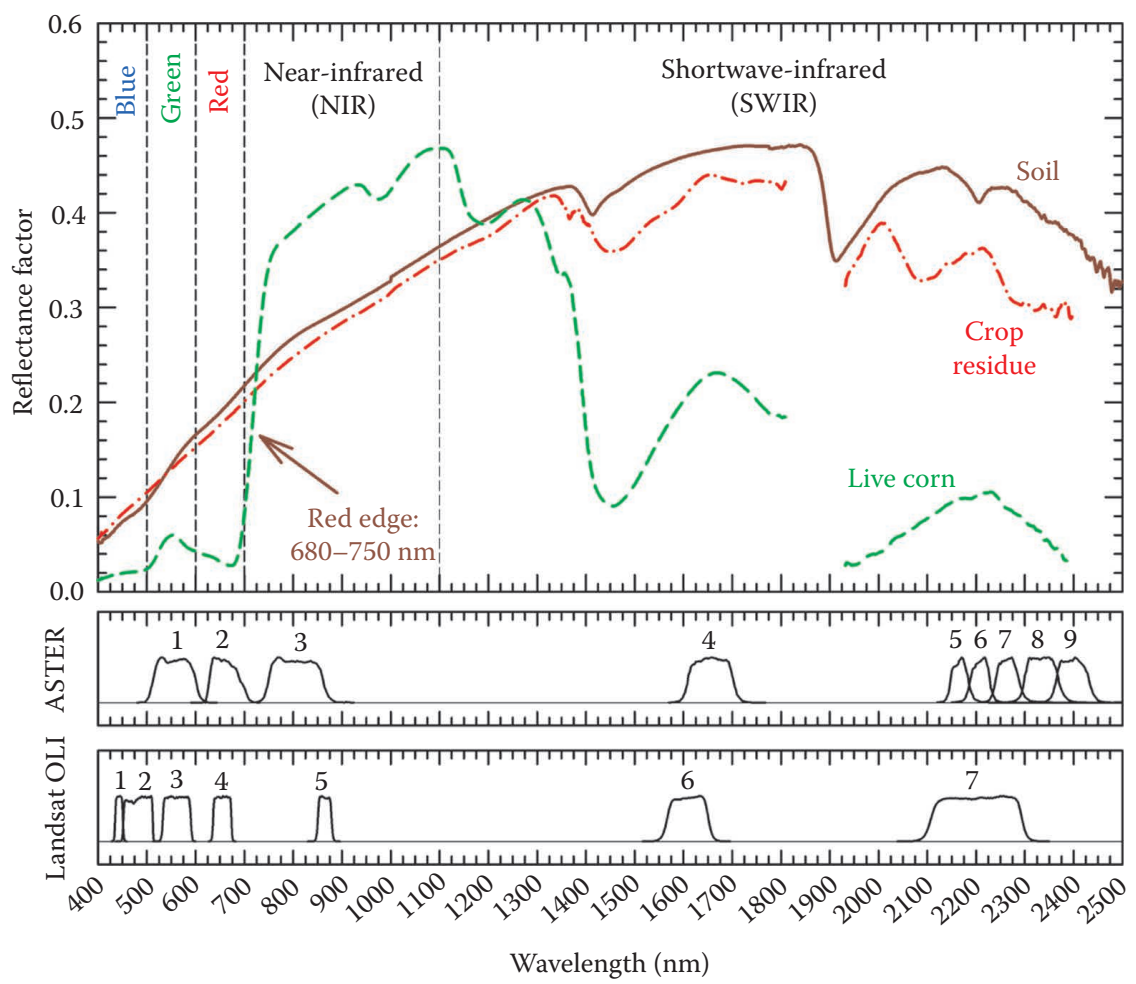

FIg u r e 8.1 Spectra of a soil, corn residue, and live corn canopy for the visible through SWIR and relative spectral response (RSR) for ASTER and Landsat OLI bands. Note that reflectance values vary from sample to sample. (Adapted from Daughtry, C.S.T. et al., Agron. J., 97(3), 864, 2005, doi: 10.2134/agronj2003.0291.) 


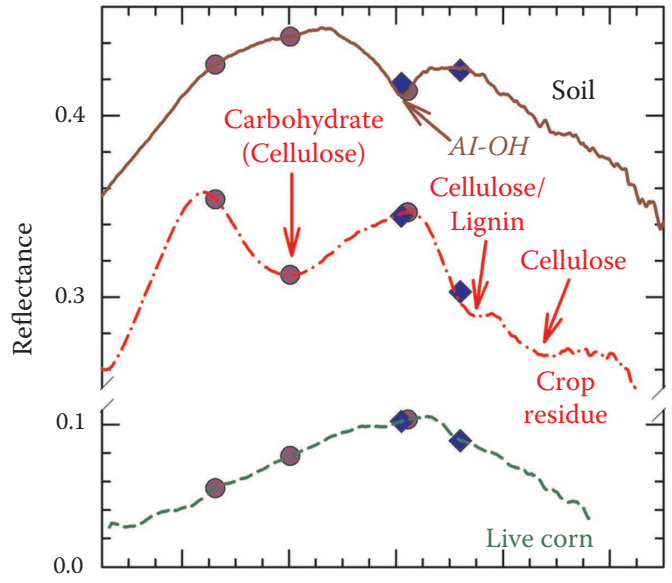

(a)

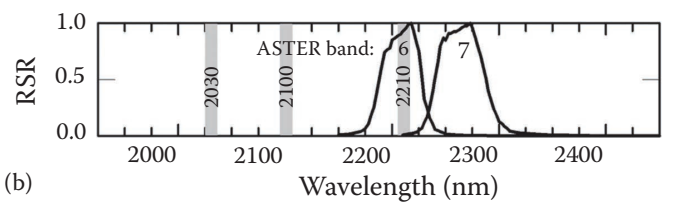

FIg u r e 8.2 (a) Spectra of a soil, corn residue, and live corn canopy in the SWIR and (b) RSR for ASTER bands 6 and 7 and $11 \mathrm{~nm}$ wide CAIbands centered at 2030, 2100, and $2210 \mathrm{~nm}$. (Adapted from Serbin, G. et al., Remote Sens. Lett., 4(6), 552, 2013, doi: 10.1080/2150704x.2013.76747p.)

which largely determines the reflectance and transmittance spectra (Thomas and Gausman 1977). In the NIR wavelength region $(700-1200 \mathrm{~nm})$, there is very little absorption, and spectral reflectance and transmittance are largely determined by leaf mesophyll structure and cell wall-air interfaces (Slaton et al. 2001). Reflectance and transmittance in the SWIR wavelength region (1200-2500 $\mathrm{nm}$ ) are affected primarily by the amount of water in the leaves (Hunt 1989; Yilmaz et al. 2008). Thus, a distinguishing spectral characteristic of green vegetation is the steplike transition from low reflectance and low transmittance in the visible region to high reflectance and transmittance in the NIR (Figure 8.1). Soils and NPV lack this spectral feature. Spectral vegetation indices that exploit this fundamental spectral feature are particularly sensitive to green vegetation, for example, the normalized difference vegetation index (NDVI) (Rouse et al. 1973; Asrar et al. 1989).

\subsubsection{Spectral Properties of n onphotosynthetic Vegetation}

NPV broadly refers to any senesced vegetation and includes crop residues, which are the portions of a cultivated crop remaining in the field after harvest. Initially, crop residues may completely cover the soil surface, but when the soil is tilled or the crop residues are harvested for feed or biofuel, crop residue cover decreases. Crop residues on the soil surface decrease soil erosion, increase soil organic matter, and improve soil quality (Lal et al. 1998). Quantification of crop residue cover is required to assess the effectiveness and extent of conservation tillage practices.
The reflectance spectra of both soils and crop residues lack the unique spectral signature of green vegetation (Figure 8.1). Crop residues and soils are spectrally similar and differ only in amplitude in the $400-1100 \mathrm{~nm}$ wavelength region, which makes quantification of crop residue cover by spectral reflectance challenging (Streck et al. 2002). Crop residues may be brighter than the soil shortly after harvest, but as residues weather and decompose, they may become either brighter or darker than the soil (Nagler et al. 2000; Daughtry et al. 2010). Residue water content also has impacts on its spectral properties. The presence of water in crop residues decreases reflectance across all wavelengths (Daughtry 2001). Thus, assessing crop residue cover with broadband multispectral data can be challenging and may require extensive local calibration data.

An alternative approach for discriminating crop residues from soils is based on detecting absorption features in the 2100-2350 nm wavelength regions that are associated with cellulose and lignin in crop residues (Workman and Weyer 2008). High residue water content can obscure the absorption feature at $2100 \mathrm{~nm}$ (Daughtry 2001). Increases in soil moisture content also decrease our ability to separate crop residue from soils (Daughtry 2001). Thus, it becomes more difficult to discriminate crop residue from soils as residue and soil water content increases. As illustrated in Figure 8.2, these absorption features are not shared by common soil minerals but are obscured by the strong absorption of water often present in soils, crop residues, and green vegetation, which can significantly attenuate the cellulose and lignin absorption features (Daughtry and Hunt 2008; Serbin et al. 2009a).

\subsubsection{Spectral indices for Assessing c rop Residue c over}

Spectral vegetation indices designed for assessing green vegetation, such as NDVI, cannot distinguish soil and crop residues. Numerous tillage or residue indices use various combinations of visible, NIR, and shortwave multispectral bands to discriminate crop residues from soils. The index best suited for crop residue cover estimation from single scenes is the cellulose absorption index (CAI), which specifically targets this feature. It has the distinct advantage that crop residues always have CAI $>0$, live vegetation $\approx 0$, and soils $\leq 0$ (Figure 8.3). The CAI is defined as the relative intensity of the absorption feature at $2100 \mathrm{~nm}$, which is attributed to an $\mathrm{O}-\mathrm{H}$ stretching and $\mathrm{C}-\mathrm{O}$ bending combination in cellulose and other carbohydrates in crop residues. CAI is measured using three relatively narrow $(10-30 \mathrm{~nm}$ spectral resolution depending on the sensors) spectral bands-two on the shoulders and one near the center of the absorption feature at $2100 \mathrm{~nm}$ (Nagler et al. 2000) (Table 8.2). CAI is effective in discriminating crop residues from soils for dry to moderately moist mixtures of crop residues and soils but less effective for mixtures of wet crop residues and soils (Daugthtry 2001).

Additional spectral indices that also target the cellulose and lignin absorption features of crop residues have used the relatively narrow (30-90 nm) SWIR bands of the Advanced 


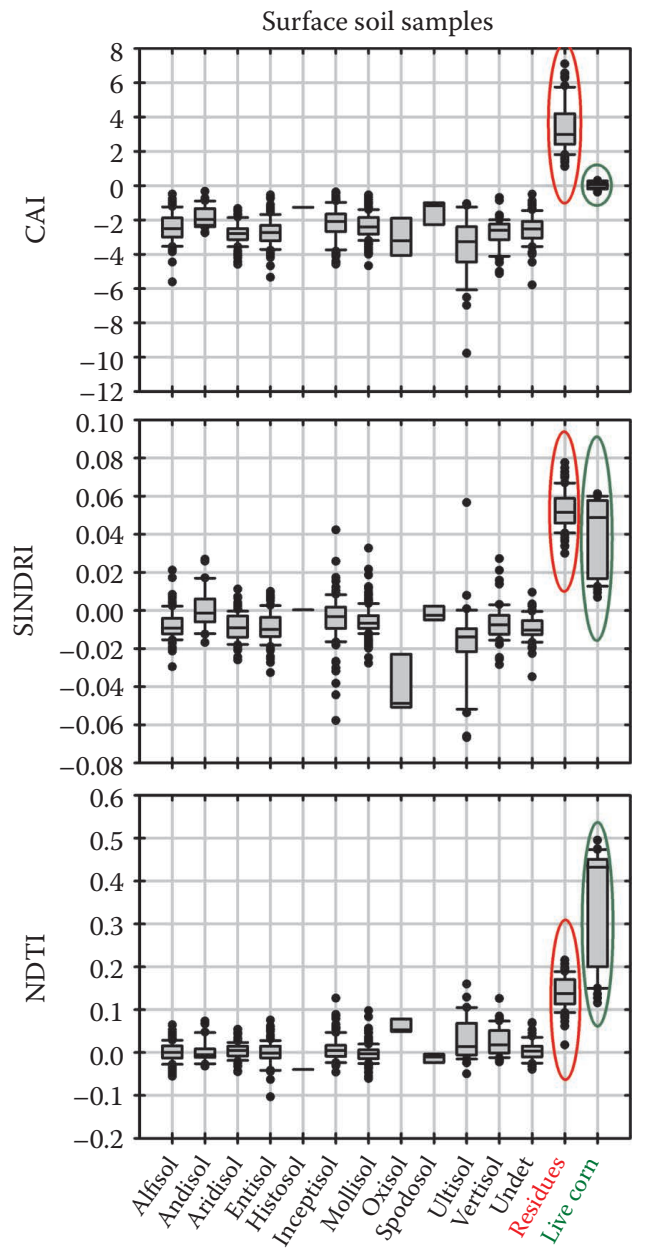

FIg u r e 8.3 Spectral index values for surface soils, crop residues, and live corn canopy. (Adapted from Serbin, G. et al., Soil Sci. Soc. Am. J., 73(5), 1545, 2009a, doi: 10.2136/sssaj2008.0311; Serbin, G. et al., Remote Sens. Lett., 4(6), 552, 2013, doi: 10.1080/2150704x.2013.767479.)

Spaceborne Thermal Emission and Reflection Radiometer (ASTER) on the NASA Terra satellite, that is, the lignin cellulose absorption (LCA) and the shortwave infrared normalized difference residue index (SINDRI) (Daughtry et al. 2005; Serbin et al. 2009c). For two-band normalized difference indices (NDIs), the ASTER-based SINDRI performs well and targets a decrease in reflectance associated with cellulose and lignin features between ASTER SWIR bands 6 and 7 (Serbin et al. 2009c; Table 8.2). However, SINDRI is sensitive to green vegetation (Figures 8.2 and 8.3) and certain soil minerals (Figure 8.4), which also

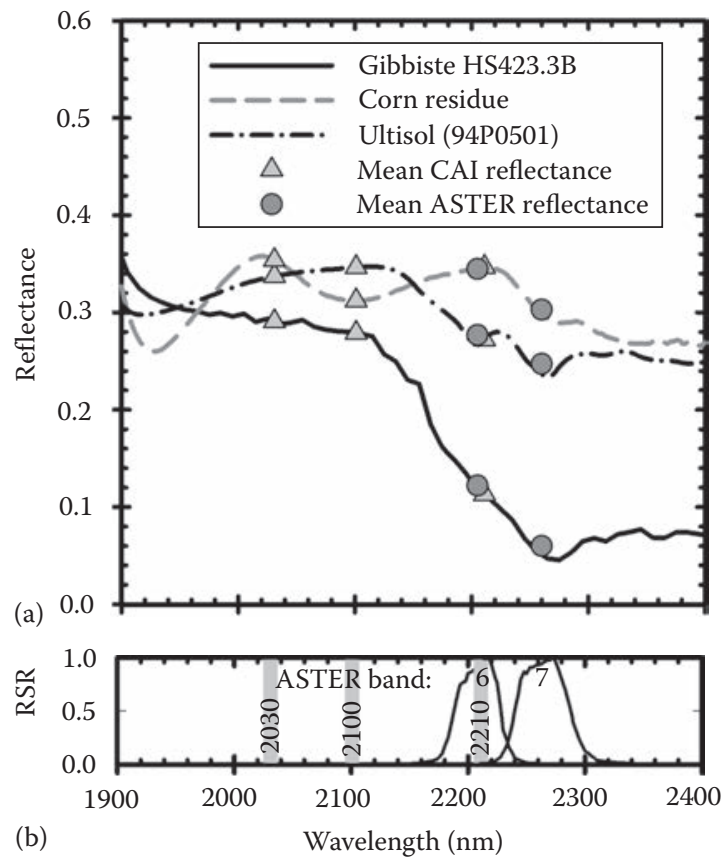

FIg u r e 8.4 (a) Spectra of Gibbsite HS423.3B (Clark et al. 2007), a gibbsitic Ultisol (Brown et al. 2006), and corn residue with convolved spectral band values. (b) Relative spectral response functions (RSR) for 11-nm wide bands centered at 2030, 2100, and $2210 \mathrm{~nm}$ (CAI), and ASTER bands 6 and 7 (SINDRI). (Adapted from Serbin, G. et al., Remote Sens. Lett., 4(6), 552, 2013, doi: 10.1080/2150704x.2013.767479.)

experience reflectance decreases between these bands, such that it may not work well for a limited number of soils or where emerged crops may be present (Serbin et al. 2013).

While Landsat Thematic Mapper (TM)/Enhanced Thematic Mapper (ETM) bands 5 and 7 and Landsat 8 Operational Land Imager (OLI) bands 6 and 7 are too wide and not properly placed to capture the cellulose absorption feature at $2100 \mathrm{~nm}$, they can be used for tillage estimation via normalized difference tillage index (NDTI) (van Deventer et al. 1997; Table 8.2). In addition to NDTI, NDI (McNairn and Protz 1993) and simple tillage index (STI) (van Deventer et al. 1997) are Landsat-based tillage indices. Serbin et al. (2009a) showed that NDTI performed the best of several Landsat-based tillage indices but underperformed in comparison to CAI and the ASTER-based LCA. Furthermore, NDTI was found to lack adequate contrast for a number of soils with high content of kaolinite or smectite and had a much stronger signal for live vegetation than either crop residues or soil minerals (Figure 8.3). In Figure 8.3, the median values of NDTI for crop residues are

TABLe 8.2 Selected Tillage Indices and Their Calculation

\begin{tabular}{|c|c|c|c|c|}
\hline Sensor & $\begin{array}{l}\text { Tillage } \\
\text { Indices }\end{array}$ & Formula & Description & References \\
\hline Landsat TM and ETM+ & NDTI & $(\mathrm{B} 5-\mathrm{B} 7) /(\mathrm{B} 5+\mathrm{B} 7)$ & B5, B7: Landsat bands 5 and 7. & Van Deventer et al. (1997) \\
\hline $\begin{array}{l}\text { AVIRIS } \\
\text { Hyperion }\end{array}$ & CAI & $\begin{array}{l}100 \times\left[0.5\left(\mathrm{R}_{2030}+\right.\right. \\
\left.\left.\mathrm{R}_{2210}\right)-\mathrm{R}_{2100}\right]\end{array}$ & $\begin{array}{l}\mathrm{R}_{2030} \text { and } \mathrm{R}_{2210} \text { are the refl ctances of the shoulders at } 2030 \\
\text { and } 2210 \mathrm{~nm} ; \mathrm{R}_{2100} \text { is at the center of the absorption. }\end{array}$ & $\begin{array}{l}\text { Daughtry et al. (2005) } \\
\text { Daughtry et al. (2006) }\end{array}$ \\
\hline ASTER & $\begin{array}{l}\text { LCA } \\
\text { SINDRI }\end{array}$ & $\begin{array}{l}100(2 \times \mathrm{B} 6-\mathrm{B} 5-\mathrm{B} 8) \\
(\mathrm{B} 6-\mathrm{B} 7) /(\mathrm{B} 6+\mathrm{B} 7)\end{array}$ & $\begin{array}{l}\text { B5, B6, B7, B8: ASTER shortwave infrared bands 5, 6, 7, } \\
\text { and } 8 \text {. }\end{array}$ & $\begin{array}{l}\text { Daughtry et al. (2005) } \\
\text { Serbin et al. (2009a) }\end{array}$ \\
\hline
\end{tabular}


consistently higher than the median values of surface soils. However, discrimination of some combinations of soils and crop residues may be difficult without adequate quantities of local data for calibration and validation. For example, the NDTI values of most crop residues may not differ significantly from NDTI values of soils with high content of kaolinite or smectite (Serbin et al. 2009a). As the fraction of green vegetation in a scene increases, NDTI also increases, which alters the estimation of crop residue cover. One approach is to exclude pixels with green vegetation using an NDVI threshold (Thoma et al. 2004; Daughtry et al. 2005). Another robust approach to reduce effects of soil and green vegetation on estimates of crop residue cover is to identify the minimum NDTI (minNDTI) values from multitemporal NDTI data, because the minNDTI values were found to be well correlated with crop residue cover (Zheng et al. 2012, 2013a). This method was found to be similar in accuracy to single collects using SINDRI or CAI (Figure 8.5) (Zheng et al. 2013a). However, as we can see in Figure 8.5 that minNDTI results in higher root mean squared errors (RMSE), NDTI is more subject to the negative influences of soil moisture and soil organic carbon than SINDRI and CAI (Zheng et al. 2013a).

\subsection{3 t illage Assessment Using Airborne and Satellite imagery}

Until recently, most assessments of crop residue cover and tillage intensity were snapshots of conditions using single dates of multispectral imagery. For example, various spectral indices using Landsat TM bands 5 and 7 successfully differentiated conventional tillage from conservation tillage using logistic regression (van Deventer et al. 1997; Gowda et al. 2001). Other classification methods (e.g., minimum distance, Mahalanobis
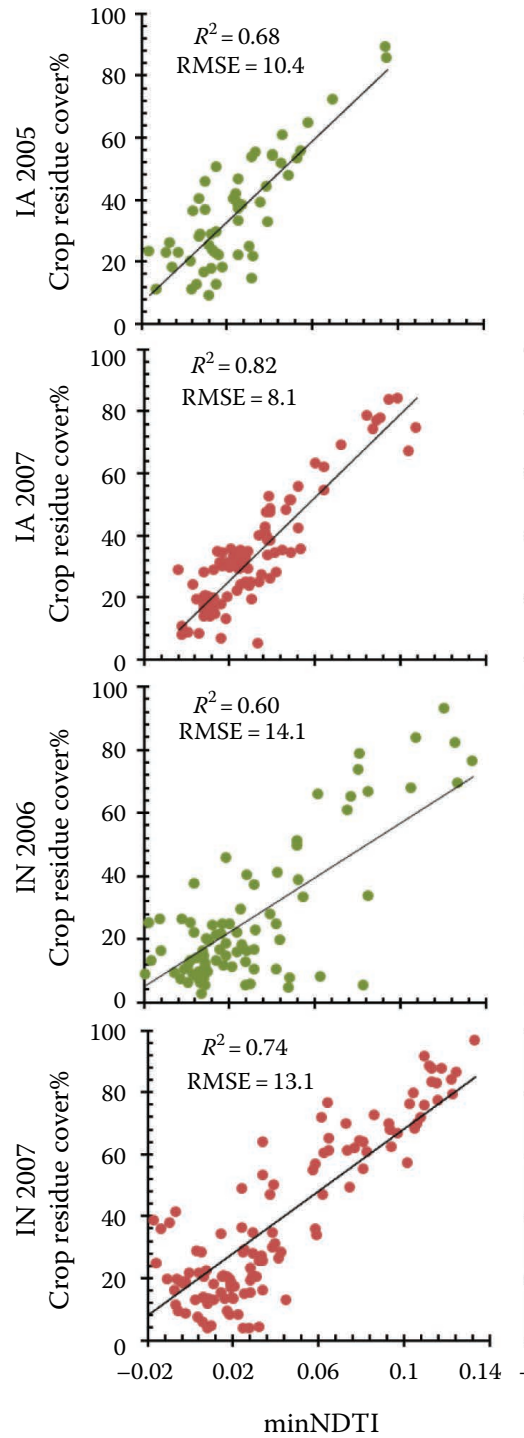
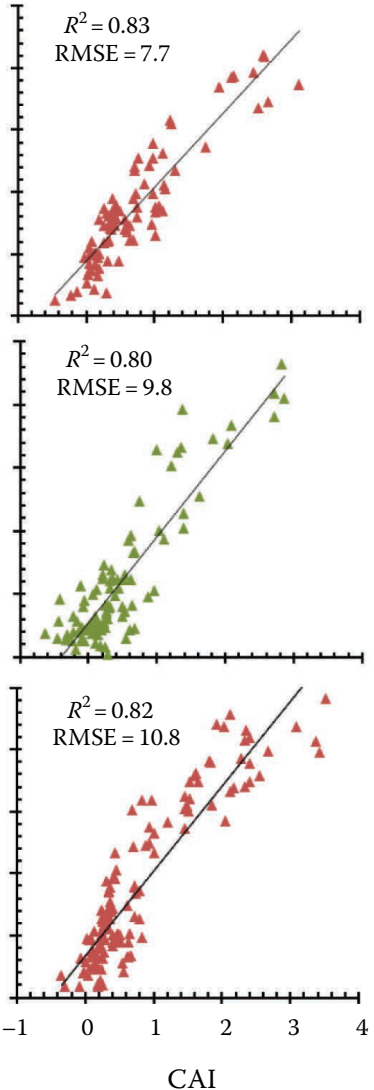
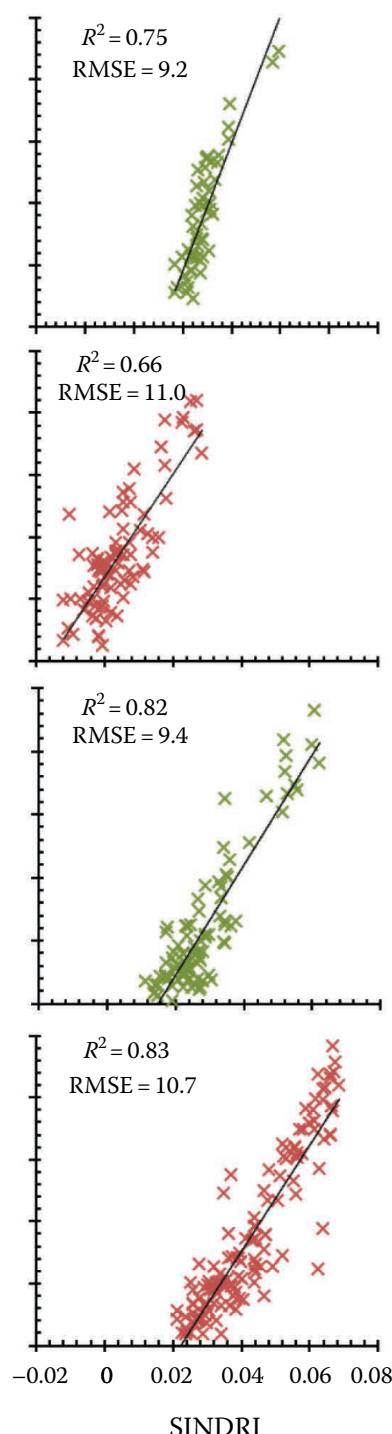

FIg u r e 8.5 Comparison of minNDTI and single-scene CAI, SINDRI, and NDTI in two study areas: Ames, IA (year 2005 and 2007), and Fulton, IN (year 2006 and 2007). (Adapted from Zheng, B. et al., J. Soil Water Conserv., 68(2), 120, 2013a.) 
distance, maximum likelihood, spectral angle mapping, and cosine of the angle concept) and data mining approaches (e.g., random forest classifier and support vector machine) have been examined for identifying two broad tillage categories (South et al. 2004; Bricklemyer et al. 2006; Watts et al. 2008; Sudheer et al. 2010; Samui et al. 2012). These studies demonstrated the capability of Landsat TM imagery to discriminate between two broad tillage categories (i.e., conventional and conservation tillage) (van Deventer et al. 1997; Gowda et al. 2001) but fell short of achieving the reliability and consistency required for operational applications. Based on previous studies, it remains unclear which classification approach performs the best in classifying tillage categories. Research also has been conducted to test the feasibility of estimating crop residue cover using Landsat data (McNairn and Protz 1993; Thoma et al. 2004; Daughtry et al. 2006). These studies used single-date multispectral images and yielded mixed results. The inconsistent results of these studies may be related to the spectral resolution of Landsat TM data, different image preprocessing strategies to correct for atmospheric transmittance, spatial and temporal variations in soils, and green vegetation.

Tillage indices developed using hyperspectral and advanced multispectral (e.g., ASTER) data have provided consistent assessments of crop residue cover across years and study sites (Table 8.3; Figure 8.5). These tillage indices (e.g., CAI, SINDRI) detect absorption features associated with cellulose and lignin and are robust for discriminating crop residues from soils and green vegetation. However, the sensor systems with the appropriate spectral bands have very limited spatial and temporal coverage, which limits their usefulness for monitoring crop residue cover and tillage intensity over large areas. Finally, the SWIR bands of ASTER needed to characterize residue cover are no longer available due to detector failure in April 2008 (NASA/JPL 2008). Spaceborne multispectral imagery, however, is favorable due to its ability to provide extended repetitive coverage of the Earth. Landsat TM/ETM+ imagery, thus, is extremely attractive for monitoring tillage practices and crop residue cover over large areas because it is freely available and provides a long-term synoptic view of the Earth with a 16-day revisit frequency.

Timing of image acquisition is very important for monitoring agricultural resources because agricultural land surfaces change rapidly as growers prepare soils for planting and as crops emerge from soils, mature, and are harvested. It is well recognized that soil and residue status change rapidly during the planting season and vary in space and time (McNairn et al. 2001; Watts et al. 2008), but tillage and crop residue mapping have been long treated as a one-time mapping effort using only one image at a time, until Watts et al. (2011) incorporated temporal dimensions into tillage mapping. Zheng et al. (2012) emphasized the need to consider varied timings of tillage and planting in tillage mapping and significantly improved mapping accuracy using multitemporal Landsat imagery (Table 8.3). Minimum NDTI values were extracted from a timeseries Landsat image that included images from 1 to 2 months before expected planting date to 1-2 months after planting date (Zheng et al. 2012). The method was designated as minNDTI and forms an effective way to minimize confounding effects of green vegetation (Zheng et al. 2012). Figure 8.6 shows a tillage map and its corresponding NDTI values of Champaign County, Illinois. The left image in Figure 8.6 is the minNDTI values extracted from a time-series NDTI image. Agricultural fields managed with conservation tillage are relatively brighter because higher levels of crop residue cover result in higher NDTI values. The multitemporal approach requires the use of surface reflectance Landsat data products, which are available from EarthExplorer (http://earthexplorer.usgs.gov/) and

TABLe 8.3 Summary of Studies in Crop Residue Estimation Using Remote-Sensing Imagery

\begin{tabular}{|c|c|c|c|c|c|}
\hline Sensor & $\mathrm{n}^{\mathrm{a}}$ & Image Dates & Indices or Methods & $\mathrm{R}^{2}$ & References \\
\hline Landsat TM & 266 & $4 / 18 / 1990$ & NDI & 0.74 & McNairn and Protz (1993) \\
\hline \multirow[t]{3}{*}{ Landsat ETM+ } & 468 & $03 / 28 / 2000$ & NDI & 0.38 & Thoma et al. (2004) \\
\hline & & $06 / 03 / 2001$ & STI & 0.47 & \\
\hline & & $11 / 10 / 2001$ & NDTI & 0.48 & \\
\hline \multirow[t]{2}{*}{ Landsat TM } & 54 & $06 / 12 / 2004$ & NDI & 0.14 & Daughtry et al. (2006) \\
\hline & & & NDTI & 0.11 & \\
\hline SPOT & Varied & Varied & Spectral unmixing & $0.58-0.78$ & Pacheco and McNairn (2010) \\
\hline Landsat TM & 39 & $05 / 28 / 2008$ & & 0.69 & \\
\hline Hyperion & 54 & $05 / 03 / 2004$ & CAI & 0.85 & Daughtry et al. (2006) \\
\hline Landsat $\mathrm{TM}^{\mathrm{b}}$ & Varied & Varied & NDTI & $0.004-0.64$ & Serbin et al. (2009c) \\
\hline \multirow[t]{2}{*}{ ASTER $^{c}$} & Varied & Varied & LCA & $0.39-0.86$ & \\
\hline & & & SINDRI & $0.61-0.87$ & \\
\hline Airborne hyperspectral data & Varied & Varied & CAI & $0.72-0.89$ & \\
\hline Landsat TM and ETM+ & 31 & Multitemporal & $\operatorname{minNDTI}$ & 0.89 & Zheng et al. (2012) \\
\hline Landsat TM and ETM+ & Varied & Multitemporal & $\operatorname{minNDTI}$ & $0.66-0.89$ & Zheng et al. (2013a) \\
\hline
\end{tabular}



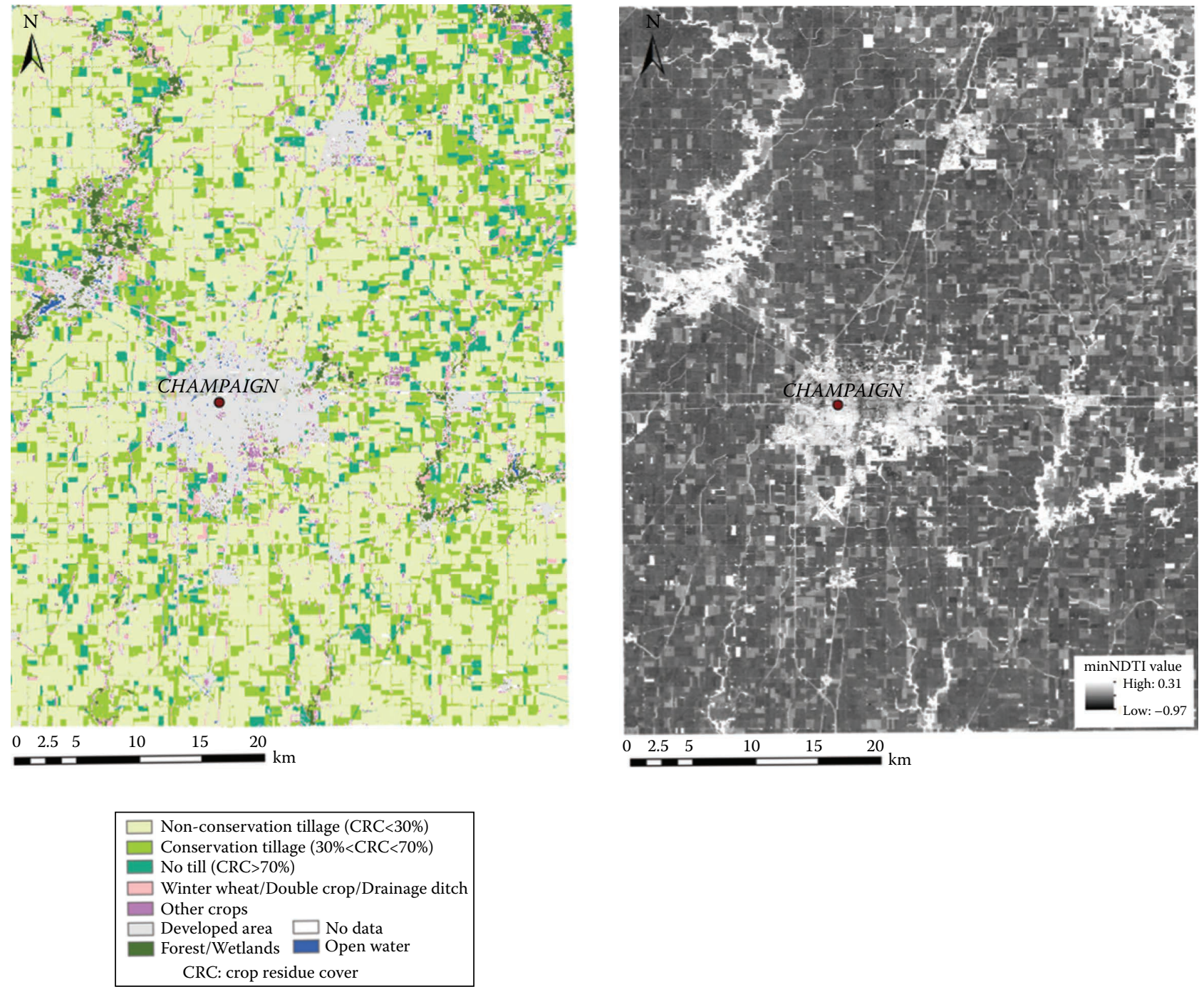

FIg u r e 8.6 2006 Tillage map of Champaign County (left), Illinois, and its corresponding minNDTI values (right) extracted from a time-series NDTI image. Agricultural fields with brighter tones indicate higher levels of crop residue cover, which corresponds to the conservation tillage category.

USGS EROS Science Processing Architecture (ESPA) ordering interface (https://espa.cr.usgs.gov). The minNDTI approach was also applied to six additional datasets collected in different regions of the United States and the technique was comparable to CAI and SINDRI in achieving similar classification accuracy of three tillage categories (Zheng et al. 2013a). Zheng et al. (2013a) reported $68 \%-86 \%$ overall accuracies for three tillage categories - a significant improvement compared to $42 \%-56 \%$ accuracies reported by Thoma et al. (2004). However, the minNDTI approach cannot address the effects of surface soil variability as its performance was degraded when applied to a larger geographical area. Nevertheless, a multitemporal approach has shown a substantial potential to track changes of tillage practices over time and space using freely available Landsat and Landsat-like data (Watts et al. 2011; Zheng et al. 2012, 2013a).

\subsubsection{Summary}

\subsubsection{1 c hallenges}

The primary challenges for operational tillage mapping using optical remote-sensing imagery include the following: (1) Revisit rates of moderate-spatial-resolution imagery are not frequent enough to capture the rapid changes in agricultural land surfaces during planting season, (2) there is limited spatial coverage of satellite hyperspectral imagery, (3) there are confounding effects of soil background and green vegetation, and (4) there is a lack of transferability of locally developed models.

Landsat is currently the best satellite system to provide the capabilities for long-term and broadscale tillage assessment. Although the minNDTI technique showed promises in tillage mapping at large scales, the 8 -day revisit rate of combined Landsat 8 OLI and 7 ETM+ cannot guarantee adequate numbers 
of cloud-free observations to capture the recently tilled surface. In tropical regions or other areas that have persistent cloud cover, one may be lucky to obtain two or three cloud-free images per year. The data gap issues of Landsat 7 ETM+ imagery also prevent rapid application of the minNDTI technique because additional image preprocessing skills are required to fill the missing data. Zheng et al. (2013b) have presented an easy way to fill the missing data for broadscale tillage mapping using the multiscale segmentation method. Landsat images with partial cloud cover can be incorporated into the time series; however, estimation of tillage status for the cloud-contaminated pixels could be less accurate, and a quality assessment map should be provided to inform users about locations of cloud and cloud shadow pixels (Zheng et al. 2014).

The spatial and temporal adaptive reflectance fusion model (STARFM) (Gao et al. 2006), which produces cloud-free synthetic Landsat images with $30 \mathrm{~m}$ spatial resolution at Moderate Imaging Spectroradiometer (MODIS) temporal frequency, could be an alternative option to enhance temporal resolution for tillage mapping. The enhanced STARFM (Zhu et al. 2010), future improvement of data fusion techniques, and the higher quality of Landsat 8 and the European Space Agency (ESA) Sentinel-2 data could open possibilities to provide data optimized in both temporal and spatial resolutions for tillage assessment. However, the potential to incorporate data fusion techniques into minNDTI technique to improve our ability to map tillage practices currently remains unknown and required for future investigation (Zheng et al. 2014).

Locally developed empirical models often show degraded performance when applied to the same location over time or to a broader region. Variations in weather, soil, and terrain conditions across landscape are the main reasons for the degraded performance when a model is extrapolated to new situations. Zheng et al. (2013a) reported superior performance of local models than a universal model and highlighted negative impacts of local variation in terrain, moisture, and soil color upon crop residue estimation. Thus, estimation of crop residue cover with broadband multispectral may require extensive local calibration data. Alternatively, the effects of soil variation can be reduced or minimized using local soil-adjusted tillage indices (Biard and Baret 1997) or the spectral unmixing approach (Pacheco and McNairn 2010). The spectral unmixing approach has the potential to map crop residue cover over large geographic regions as the approach is insensitive to variations in soil and residue when end-members are retrieved directly from the image (Pacheco and McNairn 2010). However, future work is required to examine how well the unmixing approach performs in the presence of green vegetation.

Much of the research to apply remote sensing to tillage assessment has been developed in the context of midlatitude agriculture, characterized by distinct seasonal cycles, large field sizes, common use of monoculture, or reduced crop diversity, over large regions. In other regions of the world, or in irrigated regions, there may be a much larger range of crops, with a variety of planting and harvesting dates, not synchronized with each other, and smaller field sizes—in such situations, the tillage assessment task requires different strategies than may be effective in midlatitude regions.

\subsubsection{Future c apabilities}

At the time of this writing, due to the limited availability of hyperspectral data, the minNDTI approach is probably the most effective method to map tillage practices at broadscale using optical remote-sensing imagery. The minNDTI can be applied to Landsat 7 ETM+ and Landsat 8 OLI, which together provides an 8-day observation cycle. The OLI imagery has potential to enhance our ability to accurately estimate crop residue cover with its narrower spectral bands and 12-bit dynamic range, as indicated by Galloza et al. (2013), who found that the Advanced Land Imager (ALI) has better capability to discriminate crop residues from soils than Landsat TM data.

The upcoming launch of ESA Sentinel-2 satellite will provide enhanced Landsat-type data with $<5$-day revisit time. Sentinel-2 is particularly useful for monitoring the rapid changes of agricultural lands. Operational tillage assessment is likely to involve multisensor multidate image fusion and could be implemented using Landsat and Sentinel-2 data together. The planned hyperspectral satellite missions, including ESA Environmental Mapping and Analysis Program (EnMAP) and NASA Hyperspectral Infrared Imager (HyspIRI), will also make contribution to large-scale tillage assessment. These hyperspectral data can be used to calculate CAI. Fusion of hyperspectral and multispectral images could estimate crop residue cover at the multispectral spatial extent with improved accuracy (Galloza et al. 2013). The WorldView-3 satellite launched in August 2014 includes SWIR bands equivalent to ASTER SWIR sensor (DigitalGlobe, 2014), which can be used to derive SINDRI for crop residue estimation. The very high spatial resolution $(3.7 \mathrm{~m})$ of WorldView-3 SWIR data will permit fine-scale assessment of crop residue cover, soil texture, and soil roughness.

\subsection{Monitoring with SAR}

\subsection{1 introduction}

SARs are considered active remote-sensing sensors as they generate pulses of energy that are propagated toward a target. SARs then record the energy scattered by the target, back toward the radar antenna. The strength (intensity) of the received or backscattered signal is measured as sigma naught $\left(\sigma^{0}\right)$, expressed in decibels $(\mathrm{dB})$. Since these sensors provide their own source of energy, SARs are able to collect data day or night. SARs generate energy at microwave frequencies $(0.2-300 \mathrm{GHz})$, with Earth-observing SAR satellites typically operating at X-band $(2.40-3.75 \mathrm{~cm}$; 8.0-12.5 GHz), C-band (3.75-7.5 cm; 4.0-8.0 GHz), and L-band (15-30 cm; 1.0-2.0 GHz) (Lewis and Henderson 1998) (Table 8.4). These lower frequencies are unaffected by the presence of cloud and haze. Given this context and the sensitivity of microwaves to soil conditions, SARs are an important data source for mapping and monitoring tillage and residue. 
TABLe 8.4 Selected Civilian Spaceborne Radar Sensors

\begin{tabular}{|c|c|c|c|c|c|c|c|}
\hline \multicolumn{2}{|c|}{$\begin{array}{l}\text { Frequency } \\
\text { (in GHz) }\end{array}$} & $\begin{array}{c}\text { Sensor } \\
\text { COSMO-SkyMed } 1\end{array}$ & $\begin{array}{l}\text { Polarization }^{\mathrm{a}} \\
\text { SP, DP }\end{array}$ & $\begin{array}{c}\text { Incidence } \\
\text { Angle }\left(^{\circ}\right)\end{array}$ & $\frac{\text { Resolution }(\mathrm{m})}{1-100}$ & $\frac{\text { Swath }(\mathrm{km})}{10-200}$ & $\frac{\text { Dates of Operation }}{2007-}$ \\
\hline $\mathrm{X}$ & 8.600 & $\begin{array}{l}\text { COSMO-SkyMed } 1 \\
\text { COSMO-SkyMed } 2 \\
\text { COSMO-SkyMed } 3 \\
\text { COSMO-SkyMed } 4\end{array}$ & $\begin{array}{l}\text { SP, DP } \\
\text { SP, DP } \\
\text { SP, DP } \\
\text { SP, DP }\end{array}$ & $25-50$ & & & $\begin{array}{l}2007- \\
2007- \\
2008- \\
2010-\end{array}$ \\
\hline & 8.650 & TerraSAR-X & SP, DP, QP & $15-60$ & $0.25-40$ & $4-270$ & $2007-$ \\
\hline & 8.650 & TanDEM-X & SP, DP, QP & $15-60$ & $0.25-40$ & $4-270$ & $2010-$ \\
\hline \multirow[t]{8}{*}{$\mathrm{C}$} & 5.300 & RADARSAT-1 & SP (HH) & $10-60$ & $8-100$ & $45-500$ & $1995-2013$ \\
\hline & 5.300 & ERS-2 & SP (VV) & $20-26$ & 30 & 100 & $1995-2011$ \\
\hline & 5.331 & Envisat ASAR & SP, DP & $15-45$ & $10-1000$ & $5-405$ & $2002-2012$ \\
\hline & 5.350 & RISAT-1 & SP, DP, QP, CP & $12-55$ & $1-50$ & $25-223$ & $2012-$ \\
\hline & 5.405 & RADARSAT-2 & SP, DP, QP & $10-60$ & $3-100$ & $18-500$ & $2007-$ \\
\hline & 5.405 & RADARSAT Constellation & SP, DP, QP, CP & $10-60$ & $1-500$ & $5-500$ & 2018 \\
\hline & 5.405 & Sentinel $1 \mathrm{~A}$ & SP, DP & $20-45$ & $5-40$ & $80-400$ & $2014-$ \\
\hline & & Sentinel 1B & SP, DP & $20-45$ & $5-40$ & $80-400$ & 2016 \\
\hline \multirow[t]{5}{*}{$\mathrm{L}$} & 1.200 & ALOS/PALSAR-1 & SP, DP, QP & $8-60$ & $10-100$ & $20-350$ & $2006-2011$ \\
\hline & 1.200 & ALOS/PALSAR-2 & SP, DP, QP, CP & $8-60$ & $1-100$ & $25-490$ & $2014-$ \\
\hline & 1.260 & SMAP & $\mathrm{SP}, \mathrm{VV} / \mathrm{HH} / \mathrm{HV}^{\mathrm{b}}$ & 40 & $1-3(\mathrm{~km})$ & 1000 & $2015-$ \\
\hline & 1.275 & SAOCOM $1 \mathrm{~A}$ & SP, DP, QP, CP & $17-51$ & $10-100$ & $20-350$ & 2015 \\
\hline & & SAOCOM 1B & & & & & 2016 \\
\hline
\end{tabular}

\footnotetext{
${ }^{a}$ In the polarization column, $\mathrm{SP}=$ single polarization, $\mathrm{DP}=$ dual polarization, $\mathrm{QP}=$ quadrature polarization, and $\mathrm{CP}=$ compact polarization.

b SMAP has now been launched. Thus this should say "SMAP acquires radar imagery simultaneously in VV, HH, and HV.
}

\subsection{2 c ritical Variables for $t$ illage Assessment}

The interaction of microwaves with a target and the characteristics of the scatter that results from this interaction are a function of the condition of the target as well as the SAR sensor specifications. SAR response is driven by the dielectric permittivity, roughness, and structural properties of the target. In the context of tillage monitoring, SARs are sensitive to small-scale roughness and large macrostructures produced by farming implements, as well as volumetric soil moisture. In addition to their spatial resolution, SARs are characterized by their frequency, incidence angle, and polarization-configurations that also affect the target interaction.

\subsubsection{Sensitivity of SAR to Soil $\mathrm{c}$ haracteristics}

\subsection{Surface Roughness}

Random and periodic roughness determines the angular scattering pattern with diffuse scattering increasing as roughness increases. For agricultural fields, roughness is created by land management activities (principally tillage and seedbed preparation) modified over time by water and wind erosion. Roughness is defined by two parameters: the root mean square (RMS) variance and surface correlation length $(l)$. RMS describes the surface's random vertical statistical variability relative to a reference surface; while correlation length is an autocorrelation function that measures the statistical independence of surface heights at two points (Ulaby et al. 1986). For very smooth surfaces, as expected from no-till fields, the random roughness (RMS) is small and the height of every point is correlated with the height of every other point (hence $l$ is large). In this case, most microwave energy is forward scattered and backscatter is low. Inversely randomly rough surfaces, created by tillage, result in more diffuse scattering with a greater proportion of the incident energy scattered back to the sensor. These surfaces have higher RMS, short correlation lengths, and higher backscatter.

\subsection{Dielectric Permittivity}

The intensity of backscatter from soils is largely determined by the soil permittivity (dielectric constant), while the angular pattern of microwave scattering is governed by the surface roughness. The permittivity $\varepsilon$ is a frequency-dependent complex quantity $\left[\varepsilon(f)=\varepsilon^{\prime}(f)-j \varepsilon^{\prime \prime}(f)\right]$, where the real component $\varepsilon^{\prime}$ describes the polarizability of a material when an electric field is applied and the imaginary component $\varepsilon^{\prime \prime}$ energy losses (Hasted 1973). Dielectric losses are due to relaxation $\varepsilon_{\text {ref }}^{\prime \prime}$ and direct current electrical conductivity $\sigma$ in S/m: $\varepsilon^{\prime \prime}(f)=\varepsilon_{\text {ref }}^{\prime \prime}(f)+\sigma / 2 \pi f \varepsilon_{0}$, where $\varepsilon_{0}$ is the permittivity of free space $\left(8.854 \cdot 10^{-12} \mathrm{~F} / \mathrm{m}\right)$. On agricultural fields (without vegetation cover), scattering occurs at the air/soil boundary as a dielectric discontinuity exists at this interface. The majority of dry soils have $\varepsilon^{\prime}$ of $3-8$, and bulk soil permittivity increases with water content. This is due to the much greater, albeit frequency-dependent, permittivity of water, which at $1.4 \mathrm{GHz}$ ranges from $84.1-j 10.7$ at $5^{\circ} \mathrm{C}$ to $74.5-j 4.1$ at $35^{\circ} \mathrm{C}, 69.0-j 32.1 \sim 71.4-j 14.6$ at $5.3 \mathrm{GHz}$, and $49.2-j 39.7 \sim$ $65.1-j 23.7$ at $9.6 \mathrm{GHz}$ for pure water where $s=0 \mathrm{~S} / \mathrm{m}$ for pure water where $\sigma=0 \mathrm{~S} / \mathrm{m}$. Increases in either part of the permittivity will increase soil reflectivity. Electromagnetic wavelength is an inverse function of $\varepsilon^{\prime}$; thus the wavelength becomes shorter 
within the soil as it becomes wetter. As backscatter intensity is a function of permittivity, a strong linear relationship exists between soil moisture and backscatter. The depth of sensitivity within the soil volume is dependent upon three parameters: the SAR configuration, soil moisture, and bulk soil $\varepsilon^{\prime \prime}$. Penetration depth is an inverse function of bulk soil permittivity and, thus, soil moisture and conductivity. Consequently, SARs respond to moisture over deeper volumes as soils dry. Regardless, sensitivity is still near surface with this depth approximately equivalent to the microwave wavelength (Boisvert et al. 1995).

\subsection{Residue}

If vegetation (green or senesced vegetation or postharvest residue) is present, SAR response will be affected if water is present in the vegetation. Residue is considered "dead" vegetation, and thus its effect on backscatter is often assumed insignificant, effectively transparent to the incident microwaves. This assumption has proven invalid in circumstances where residue retains water. The impact of residue on backscatter varies depending upon the volume of water held, a function of the amount and type of residue (McNairn et al. 2001). Jackson and O’Neill (1991) reported that residue can retain significant moisture with McNairn et al. (2001) measuring up to $60 \%$ and $40 \%-50 \%$ moisture in corn and barley residue, respectively, following rain events.

\subsection{Row Direction}

Land management practices (planting, harvesting, and tillage) can create row effects and row direction relative to the radar look direction impacts SAR response. When row direction is perpendicular to the look direction, SAR response is stronger when compared to a look direction parallel to rows (Beaudoin et al. 1990; McNairn et al. 1996). Producers follow a rectangular pattern operating parallel to the long and short axes of fields. This practice creates a "bow-tie" effect visible on SAR imagery where, within a single field, backscatter is significantly higher for the axis of the field oriented perpendicular to the sensor.

\subsubsection{2 impact of SAR c onfiguration}

SAR sensors are defined by three configurations-frequency ( $\mathrm{GHz}$, or $\mathrm{cm}$, if characterized as free-space wavelength), incidence angle (degrees), and polarization. These configurations affect how microwaves interact with the target in terms of backscatter intensity and scattering characteristics. SAR configurations can be selected to maximize sensitivity to the target property of interest (soil moisture, surface roughness, or residue). Alternatively, as these properties are confounded in the microwave signal, multiple configurations can be used together to resolve individual contributions.

\subsection{Frequency}

As well as affecting penetration depth, SAR frequency determines sensitivity to surface roughness. Thus, surface roughness must be considered relative to frequency. Surfaces are defined as rough or smooth according to the Rayleigh criterion. Surfaces are smooth if $h<\lambda / 25 \sin \tau$ and rough if $h>\lambda / 4.4 \sin \tau$ where $h$ is the RMS, $\lambda$ is the wavelength, and $\tau$ is the depression angle (Sabins 1986). Assuming flat terrain, $\tau$ is the complement of the incidence angle $(\theta=90-\tau)$. In practice, this means that a field will appear rougher (higher backscatter) at shorter wavelengths (i.e., X-band) than at longer wavelengths (i.e., L-band). With this strong dependency, the choice of wavelength is especially important when monitoring tillage. Short-wavelength (highfrequency) SARs will see many fields as rough and thus may not differentiate among tillage classes at the upper ranges of roughness. Several studies (Pacheco et al. 2010; Aubert et al. 2011; Panciera et al. 2013) reported that X-band data from TerraSAR-X were not well suited for roughness mapping when RMS was high. Panciera et al. (2013) found that TerraSAR-X backscatter was sensitive to roughness (RMS), which fell between 0.5 and $1.5 \mathrm{~cm}$, but that the signal saturated beyond $2 \mathrm{~cm}$. Conversely, large-wavelength (low-frequency) SARs may view even tilled fields as smooth. Nevertheless, numerous studies have reported sensitivity of C- and L-band responses to roughness and residue (McNairn et al. 2001, 2002; Baghdadi et al. 2008). Baghdadi et al. (2008) compared three frequencies (X-, C-, and L-band) demonstrating that sensitivity to roughness increased with wavelength.

\subsection{Incidence Angle}

Regardless of the target, backscatter decreases with increasing incidence angle, which is defined as the angle between the radar beam and a line perpendicular to the surface. The rate of decrease is target dependent, with backscatter decreasing with angle at a higher rate when soils are smooth. This differential rate of decrease can be used to separate smooth from rough fields, if fields are imaged at contrasting incidence angles (McNairn et al. 1996). As simultaneous multiangle data are typically unavailable from spaceborne SARs, a simpler approach is to select an incidence angle that maximizes sensitivity to surface roughness. Steeper (smaller) angles minimize roughness contributions to backscatter and are thus more suited to estimate soil moisture, while shallower (larger) angles maximize roughness effects on backscatter (McNairn et al. 1996). Similarly, larger angles are more sensitive to residue as soil moisture contributions are minimized, and more microwave interaction occurs with residue at these angles (McNairn et al. 2001). Although these larger angles are more suited to roughness and residue applications, contributions from soil moisture are not completely eliminated. Aubert et al. (2011) noted that the range in X-HH backscatter due to surface roughness increased as incidence angle increased, with backscatter varying 3.5 and $1.9 \mathrm{~dB}$ at angles of $50^{\circ}$ and $25^{\circ}$, respectively. Baghdadi et al. (2008) reported a slightly larger range in X-band backscatter $\left(5.5 \mathrm{~dB}\right.$ at $50^{\circ}-52^{\circ}$ and $4 \mathrm{~dB}$ at $\left.26^{\circ}-28^{\circ}\right)$.

\subsection{Polarization}

Polarization is defi ed by the orientation of the electric fi ld vectors of the transmitted and received electromagnetic wave. Polarization should be considered relative to the target structure and response interpreted according to the characteristics of scattering from the target, including the sources of scattering and the randomness of the scatter. Scattering is categorized as single 
bounce (surface), multiple (volume), or double bounce. Targets usually produce more than one type of scattering although typically one source dominates. For smooth soils devoid of residue, surface single-bounce scattering dominates. Rough soils result in multiple scattering of microwaves. Residue (depending on the amount and water content) also causes multiple scattering and, if residue is vertically oriented, double-bounce events may also contribute.

Most SAR sensors transmit and receive microwaves in the horizontal $(\mathrm{H})$ and/or vertical $(\mathrm{V})$ linear polarizations (Table 8.4). Early satellites transmitted and received microwaves in a single linear polarization (European Remote Sensing [ERS]-1 and 2 [VV], Japanese Earth Resources Satellite [JERS]-1 $[\mathrm{HH}]$, and RADARSAT-1 [HH]). Next-generation sensors (i.e., Advanced Synthetic Aperture Radar [Envisat ASAR]) transmitted and/or received in both linear polarizations, which permitted acquisition of like ( $\mathrm{HH}$ and/or VV) and cross ( $\mathrm{HV}$ or $\mathrm{VH})$ polarizations. When targets are physically oriented parallel to the polarization of the incident wave, greater microwave interaction occurs. This is most obvious for targets like crops where their vertical structure aligns well with vertical transmitted waves. Consequently, a VV configuration provides more information on crops than $\mathrm{HH}$. For soils without residue, horizontal or vertical orientation is absent and thus $\mathrm{HH}$ and VV backscatter is correlated. A linear cross polarization response ( $\mathrm{HV}$ or $\mathrm{VH}$ ) results when the transmitted wave (i.e., $\mathrm{H}$ ) is repolarized to its orthogonal polarization (i.e., V). Repolarization of $\mathrm{H}$ to $\mathrm{V}$ (or $\mathrm{V}$ to $\mathrm{H}$ ) occurs as a result of multiple scattering (at least two bounces), and thus a target must be able to cause more than a single scatter event to elicit an $\mathrm{HV}$ or VH response. Smooth soils, devoid of structure, are dominated by single-bounce forward scattering and produce very low cross-polarized backscatter. For soils with random roughness or residue (assuming moisture in the residue), incident waves experience multiple scattering and higher cross polarization response is observed. McNairn et al. (2001) reported that, of all the linear polarizations, the cross polarization was most sensitive to the amount of residue. The cross polarization has the advantage of being insensitive to planting, harvesting, or tillage row direction (McNairn and Brisco 2004). This is important considering that Brisco et al. (1991) established that row direction from tillage significantly impacted like-polarized backscatter.

\subsection{Polarimetry}

Some satellites (i.e., ALOS PALSAR, RADARSAT-2, and TerraSAR-X) are polarimetric capable. Polarimetric sensors capture the complete characterization of the scattering field meaning that they record all four mutually coherent channels $\mathrm{HH}$, $\mathrm{VV}, \mathrm{HV}$, and $\mathrm{VH}$ ), with phase information between orthogonal polarizations retained and processed. Any linear, elliptical, or circular polarization can be synthesized from polarimetric data. Circular polarizations are described by their handedness (direction of rotation) relative to the observer. Right-handed circular waves $(\mathrm{R})$ rotate clockwise (relative to observer), while left-handed waves $(\mathrm{L})$ rotate counterclockwise. The application of circular polarizations for agriculture has received limited attention although for soils, circular and linear backscatter is highly correlated (Sokol et al. 2004). As with linear polarizations, multiple scattering must occur to change the handedness of the transmitted circular polarization. Roughness or residue can cause two or more bounces, changing the handedness and resulting in a higher circular copolarization ( $R R$ or $L L$ ) response (recall rotation is defined relative to the observer). Indeed, de Matthaeis et al. (1992) observed high circular cross-polarized backscatter (LR) returns for surfaces with dominant surface scattering. Circular copolarized (RR) backscatter increases when the mechanisms producing volume scattering dominate (McNairn et al. 2002).

Polarimetric data can be processed to extract additional parameters, which characterize scattering and thus tillage and residue conditions. SARs transmit completely polarized waves but with multiple scattering, microwaves become completely or partially depolarized. The degree of depolarization (or proportion of unpolarized energy) is indicative of the randomness of scattering within the target. Smooth soils create little depolarization (Evans and Smith 1991). The degree of depolarization increases with roughness and residue cover as the phase becomes unpredictable from point to point within the target. The degree of depolarization can be measured by pedestal height with height increasing as roughness increases or in the presence of residue (van Zyl 1989; de Matthaeis et al. 1991; McNairn et al. 2002; Adams et al. 2013a). Adams et al. (2013a) also reported that the dynamic range of the degree of polarization $\left(\Delta_{\mathrm{POL}}\right)$ was sensitive to roughness and residue. $\Delta_{\mathrm{POL}}$ is the difference between the maximum and minimum degree of polarization and reflects the heterogeneity of scattering mechanisms within the target (Touzi et al. 1992).

Absolute phase $(\varphi)$ of a scattered wave is a function of distance from the target and carries no target scattering information (Langman and Inggs 1994). However, the difference in the phase between two orthogonal polarizations (i.e., $\mathrm{H}$ and $\mathrm{V}$ ) is of interest for tillage monitoring. Shifts in the phase (characterized by the copolarized phase difference $[\mathrm{PPD}]\left[\varphi_{\mathrm{VV}}-\varphi_{\mathrm{HH}}\right]$ ) occur due to double-bounce or multiple scattering. For smooth soils with minimal contributions from multiple scattering, $\mathrm{HH}$ and VV are in phase and mean PPD is close to zero (Evans et al. 1988). A vertical structure can cause a double bounce and here PPD values approach $180^{\circ}$ (de Matthaeis et al. 1991). Large phase differences are typically associated with cropped fields although high PPD values have been observed for standing senesced crops (McNairn et al. 2002). Ulaby et al. (1987) reported that plowed and disked fields, as well as those with corn and soybean residue, had a mean PPD close to zero. However, the standard deviation of the phase difference among the disked, plowed, residue and standing crops was very different. These results were confirmed by McNairn et al. (2002) where multiple scattering in residue caused a highly varying PPD with a noise-like distribution for these fields. The copolarized complex correlation coefficient $\left(\rho_{\mathrm{HH}-\mathrm{VV}}\right)$ measures the decorrelation of the phase and some sensitivity to residue has also been reported (Adams et al. 2013a). 
Methods that decompose the SAR signal have drawn considerable interest with the Cloude-Pottier (Cloude and Pottier 1997) and Freeman-Durden (Freeman and Durden 1998) decompositions showing sensitivity to tillage and residue. Cloude-Pottier decomposes the signal into a set of eigenvectors (which characterize the scattering mechanism) and eigenvalues (which estimate the intensity of each mechanism) (Alberga et al. 2008). From the eigenvalues, entropy $(\mathrm{H})$ and anisotropy $(\mathrm{A})$ are calculated. $\mathrm{H}$ measures the degree of randomness of the scattering (from 0 to 1 ); values near zero are characteristic of single scatter targets (i.e., smooth soils). Rough soils and those with residue have larger contributions from multiple scattering. This increase in randomness of scattering is measured as an increase in $\mathrm{H}$. Anisotropy estimates the relative importance of the dominant scattering mechanism and the contribution from secondary and tertiary scattering mechanisms. Zero A identifies two mechanisms of approximately equal proportions, while values approaching 1 indicate that the second mechanism dominates the third (Lee and Pottier 2009). The Cloude-Pottier decomposition also calculates the average alpha $(\bar{\alpha})$ angle $\left(0^{\circ}-90^{\circ}\right)$, which identifies the dominant scattering source (Alberga et al. 2008). Smooth soils with single-bounce scattering have angles close to $0^{\circ}$, volume scatterers close to $45^{\circ}$, and double bounce nearing $90^{\circ}$. Adams et al. (2013a) reported that $\mathrm{H}$ and $\bar{\alpha}$ were significantly correlated with roughness and percent crop residue. The Freeman-Durden decomposition separates the total power of every SAR resolution cell into contributions from three scattering mechanisms - volume (multiple), double-bounce, and single-bounce (surface) scattering. Adams et al. (2013b) demonstrated that $H, \bar{\alpha}$, and the Freeman-Durden multiple scattering could statistically separate fields with different harvesting, tillage, and residue conditions, particularly at higher incidence angles $\left(49^{\circ}\right)$. In addition, the best separability was found between unharvested or fields not tilled and conventionally tilled fields; fields under conservation tillage were confused with other tillage classes (Adams et al. 2013b).

\subsubsection{Methods}

\subsubsection{1 c hange Detection and c lassification}

Change detection identifies and measures differences between two (or more) images, indicated by a change in SAR response or in derived surface properties (roughness, residue). Several SAR metrics can be used to capture change and include (1) incoherent SAR backscatter ( $\mathrm{HH}, \mathrm{VV}, \mathrm{HV}$, and VH), (2) degree of polarization, (3) copolarized phase parameters, (4) decomposition parameters, and (5) coherent change. When change is measured directly from SAR response, consideration must be given to the confounding effects of target parameters, SAR configuration, and sensor calibration. To isolate change in SAR response due to roughness (or residue), soil moisture must not vary and thus the period between acquisitions should be minimized. Since frequency, incidence angle, and polarization affect target interaction, images must have the exact same SAR configuration. For spaceborne SARs, this means using exact repeat orbits. Constellations of satellites (such as the planned Canadian
RADARSAT Constellation) will be of interest for change detection since repeat acquisitions in the same SAR configuration will be possible within a short period of time. Finally, SARs must be well calibrated; scene to scene calibration of spaceborne sensors is typically well below $1 \mathrm{~dB}$. If changes in derived properties (roughness, residue) are used, errors in methods or model performance will be carried forward in the change detection process. Whatever metric is adopted, interpretation of the change is required. This means that a threshold must be determined, above which change is considered significant. In addition, change must be linked to information meaningful for tillage monitoring (type of implement used, tillage or residue class, change in residue amount).

McNairn et al. (1998) applied a simple change detection approach to a pair of RADARSAT-1 (HH) images acquired one week apart. The incidence angle difference between the Standard Mode 2 and 3 images was limited to $6^{\circ}$ and was considered of secondary importance. In the one week separating the first from second acquisition, $\mathrm{C}-\mathrm{HH}$ backscatter remained stable (average difference of $0.7 \mathrm{~dB}$ ) for fields not tilled. No rain fell during the week, and the small difference was attributed to the $6^{\circ}$ difference in angles. For fields that were tilled, the average change (increase) in backscatter was $5.6 \mathrm{~dB}$. This technique (Figure 8.7) enabled the identification of broad conservation tillage classes (no-till, intermediate, and tilled) and flagged fields where harvesting and tillage had occurred. Hadria et al. (2008) combined SAR (Envisat ASAR) and optical data to classify broad categories of tillage. The authors used a combination of image thresholding and decision tree classification. Envisat ASAR was especially helpful at differentiating smooth surfaces (no-till) from other rougher (tilled) surfaces.

Coherent change detection (CCD) exploits the coherence between two polarimetric complex images acquired at diffe ent times but in the same imaging geometry (Milisavljević et al.2010). A pixel-by-pixel correlation of the coherence between the images reveals changes in the target; if no change has taken place, the pixels remain correlated. This technique requires that the target is coherent, allowing changes in coherence from image to image to be measured. Random phase characterizes most distributed natural targets like forests and crops. These targets typically have low coherence and are not ideal candidates for this method. As well, external eff cts like wind can cause these targets to temporally decorrelate. Polarimetric interferometric (PolInSAR) may be useful in optimizing coherence for detecting change in distributed targets like crops (Li et al. 2014). Although CCD for tillage change detection has not been explored, this approach may be capable of observing changes from tillage activities.

\subsubsection{Semiempirical and Physical Models}

Physical scattering models estimate backscatter using the soil's physical properties and sensor configurations. Soil properties include the dielectric constant, RMS, and correlation length. The small perturbation and Kirchhoff models (geometrical optics and physical optics models) are two common physical models. However, these models are not suited to targets with 

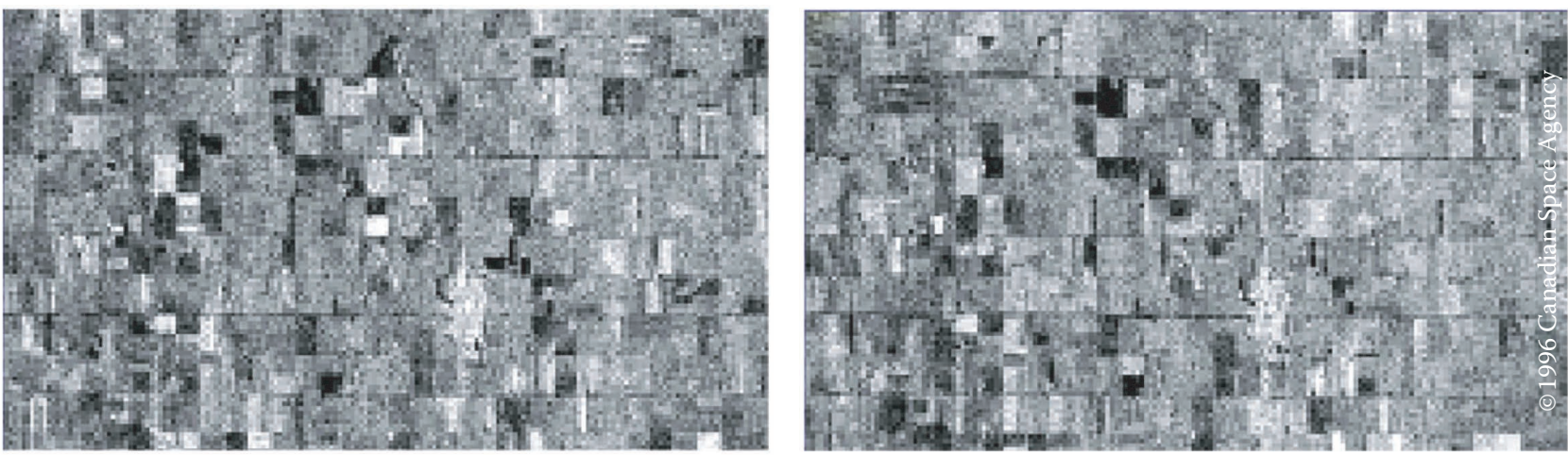

(a)

(b)
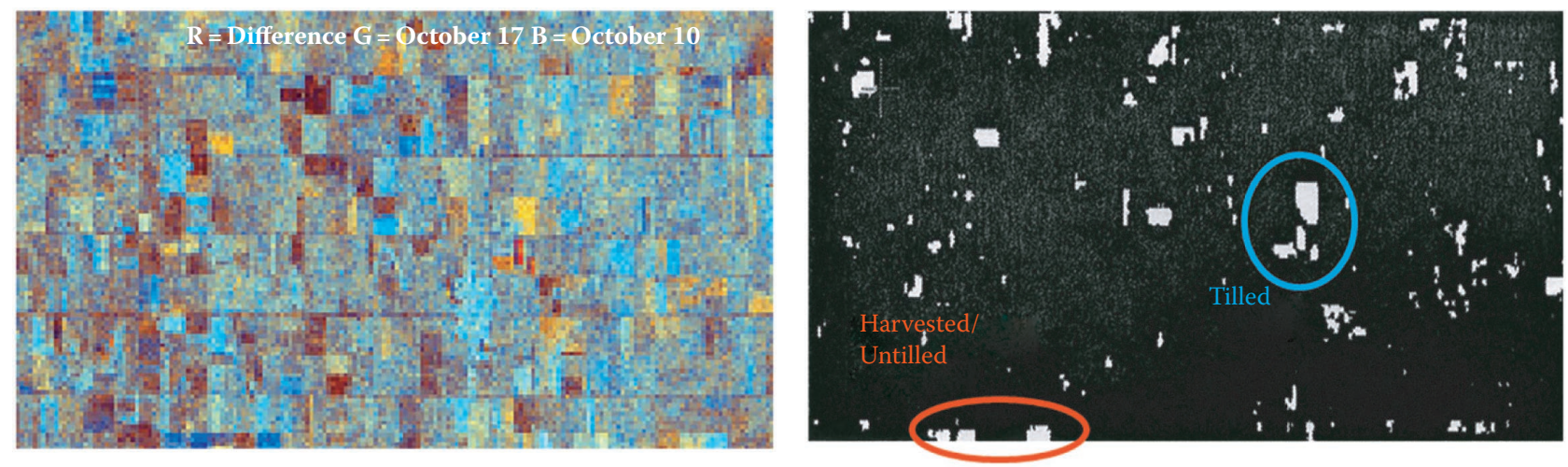

(c)

(d)

FIg u r e 8.7 Detection of tillage and harvesting activities using RADARSAT-1 over an agricultural site in Canada (Altona, Manitoba). Standard beam mode images were collected on October 10 (a) and October 17 (b) in 1996. A difference image (c) and a change detection product (d) were produced from the backscatter. (Adapted from McNairn, H. et al., Can. J. Remote Sens., 24, 28, 1998.)

multiple sources of scattering and large ranges of roughness, as expected from agricultural fields. The Integral Equation Model (IEM) (Fung et al. 1992) integrates these two models and is better adapted for targets with surface and multiple scattering and with roughness ranging from smooth to rough.

The goodness of fit between backscatter predicted by the IEM and that observed by SARs has varied depending on the roughness, frequency, and incidence angle. Speculation has been that in many cases, the error in IEM-simulated backscatter is due to inaccurate representation of the correlation length $(l)$, a parameter difficult to adequately measure in the field (Merzouki et al. 2010). As a solution, Baghdadi et al. (2004) proposed a calibrated version of the IEM, introducing an optimum correlation length $\left(l_{\text {opt }}\right)$. The optimum correlation length is derived from a set of equations that relates correlation length ( $l$ ) to RMS, as a function of polarization and incidence angle (Baghdadi et al. 2006). Simulated backscatter from the calibrated IEM has more closely matched backscatter from the C-band SAR backscatter (Merzouki et al. 2010). Figure 8.8a is an example of a surface roughness (RMS height [hRMS]) map derived from this study (Merzouki et al. 2010). Rahman et al. (2008) also derived surface roughness over sparsely vegetated fields using Envisat ASAR and the IEM in a multiangle approach. The image-derived RMS $(2.19 \mathrm{~cm})$ overestimated the field-derived RMS $(0.79 \mathrm{~cm})$
(Figure 8.8b). The subsurface rock fragments may have caused multiple bounce interactions, thus increasing response and generating a larger radar-perceived roughness (Rahman et al. 2008).

Inversion of the IEM or calibrated IEM is difficult due to the complexity of the model. As well, multiple unknowns in the IEM (dielectric constant, RMS, and $l$ ) and the calibrated IEM (dielectric constant and RMS) require multiple sources of SAR information. In this case, a lookup table (LUT) approach can be used to estimate roughness or dielectric from SAR response (Merzouki et al. 2011). Forward runs of the model are used to create the LUTs with incremental steps in dielectric, RMS, $l$, and incidence angle and their modeled backscatter (in $\mathrm{HH}$ and VV). Direct search functions are used to find the LUT entry that minimizes the difference between the measured (from SAR sensor) and modeled (from IEM) backscatter. This LUT entry provides the model estimate of soil dielectric and surface roughness. With multiple unknowns, multiple SAR configurations are needed to solve the IEM (three unknowns) or calibrated IEM (two unknowns). Typically, SAR data acquired at two polarizations (i.e., $\mathrm{HH}$ and VV) are used with the calibrated IEM. With a third unknown $(l)$, an additional source of backscatter is needed to implement the original IEM. One approach is to use SAR data acquired at two polarizations ( $\mathrm{HH}$ and $\mathrm{VV}$ ) and two contrasting incidence angles. 


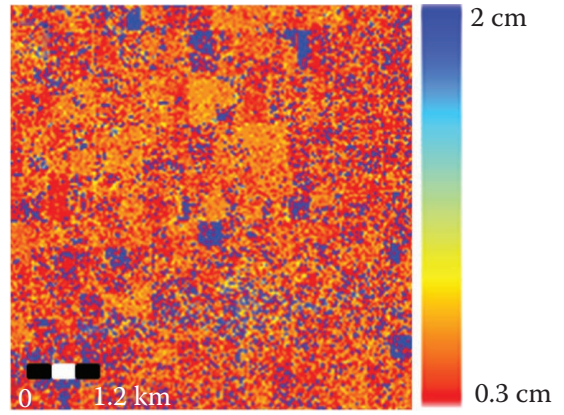

(a)

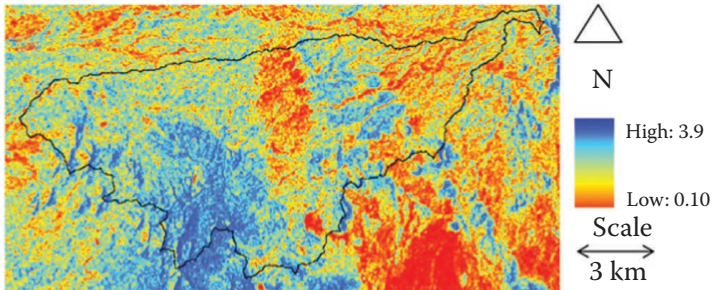

(b)

FIg u r e 8.8 Surface roughness maps derived from radar images and the IEM over two agricultural sites: an area within the Red River Watershed in Southern Manitoba in Canada (a) and Walnut Gulch Experimental Watershed in Arizona in the United States (b). The surface roughness map for the Red River Watershed is expressed in hRMS in centimeters. (Adapted from Merzouki et al. 2010.) The Walnut Gulch Experimental Watershed surface roughness map is defined by the hRMS variation of the surface at centimeter scale. The solid line represents the boundary of the Watershed. (Adapted from Rahman, M.M., et al., Remote Sens. Environ., 112(2), 391, 2008, doi:10.1016/j.rse.2006.10.026.)

The Oh (Oh et al. 1992; Oh 2004) and Dubois (Dubois et al. 1995) models are semiempirical models created from the collection of large experimental datasets and subsequently empirically relating soil dielectric (directly or via the Fresnel reflectivity), RMS, the wavelength (through the wave number), and the incidence angle to SAR backscatter. Oh modeled backscatter from all three linear polarizations $(\mathrm{HH}, \mathrm{VV}$, and $\mathrm{HV})$ and for three frequencies ( $\mathrm{X}, \mathrm{C}$, and $\mathrm{L})$. In contrast, the Dubois model uses only the copolarized backscatter ( $\mathrm{HH}$ and VV) and was developed using data collected only at L-band. As with the IEM, the Oh model can be inverted using a LUT. The Dubois model is easily inverted by solving the model's two backscatter equations. Because these models were created with experimental data, application of these models to target conditions or SAR configurations beyond those of the experimental data used to create them may yield uncertain results. Indeed, Merzouki et al. (2010) found that these models tended to overestimate backscatter when modeled backscatter was compared to that measured by RADARSAT-2, which would lead to an overestimation of RMS. The Oh model resulted in larger errors between modeled and measured backscatter on smoother fields $(<2 \mathrm{~cm})$. Conversely, errors were greater on rougher fields $(>1.5 \mathrm{~cm})$ for the Dubois model.

Hajnsek et al. (2003) developed a model to invert surface roughness by coupling a Bragg scattering term and a roughness variable derived from the scattering entropy, anisotropy and alpha angle. This model was validated against airborne polarimetric L-band (E-SAR) data and yielded low RMSE (19\%). Figure 8.9 shows a roughness map created using this approach.

\subsubsection{Linking Radar Products to $t$ illage information}

SAR sensors can provide information on roughness (RMS) and residue, as well as changes in these conditions. However, to be meaningful, roughness and residue must be linked to information of interest such as tillage implement or tillage class. This linkage is required for applications such as watershed management, soil erosion risk assessment or estimation of carbon sequestration. Establishing this linkage is not a simple task given the complexity and dynamics of tillage activities. Producers use a combination of tillage implements and tillage occurs periodically and at a range of soil depths and directions. Tillageinduced roughness also varies depending upon soil texture and moisture and is modified over time by erosion events. Winter crops and weeds present on fields also complicate tillage mapping. How to link SAR-derived products and tillage information will vary depending on the approach used to create these products. For example, if models are used to estimate roughness (RMS), an association between RMS and tillage operation could be established. Such an approach was proposed by Jackson et al. (1997). However, the roughness (RMS) created by each tillage implement, and sequences of tillage applications, is likely to vary field to field due to soil conditions, erosion, and characteristics of the implement itself. Consequently, a much larger database of roughness responses to tillage is required, and these data must be acquired over regions with varying tillage systems. For example, Pacheco et al. (2010) found that in eastern Canada, some conservation tilled fields (chiseled plowed) had greater roughness (RMS) than conventional tilled fields (moldboard plowed). As well, RMS varied greatly within the chisel class, creating confusion when attempting to use backscatter to identify classes. Classifications or change detection approaches typically identify broad tillage classes (untilled, conservation, and conventional). While these classes may be useful for some mapping applications (identifying adoption of no-till for carbon sequestration), they may not be adequate for others (erosion modeling).

\subsubsection{Summary}

Given the dynamics of tillage activities during the preseeding and postharvest seasons, SAR sensors can be a valuable data source for time-critical applications (McNairn et al. 1998). With longer wavelengths, SAR data acquisition is unaffected by atmospheric 


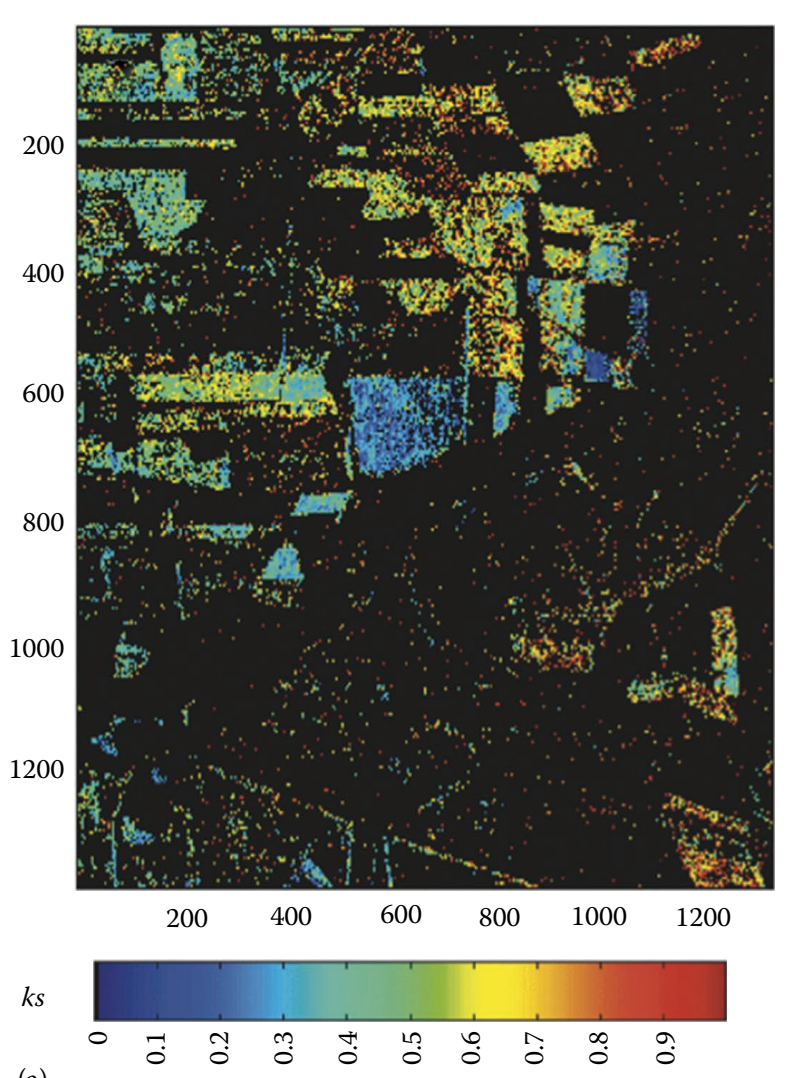

(a)

(b)

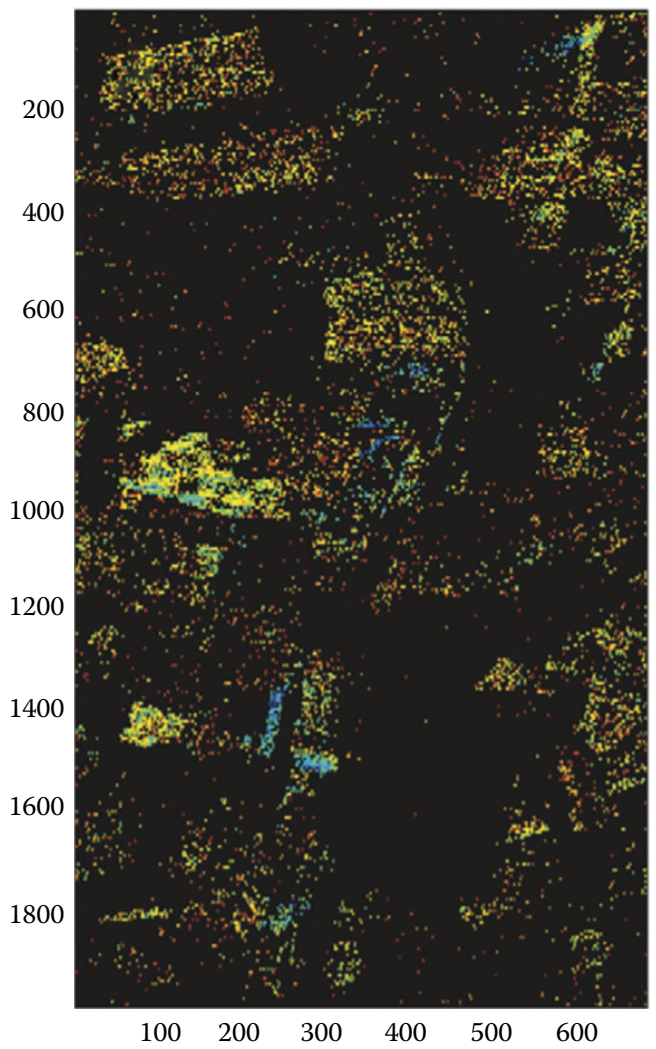

$\begin{array}{llllll}100 & 200 & 300 & 400 & 500 & 600\end{array}$

FIg u r e 8.9 Estimated surface roughness, ranging from 0 to 1, over two study sites in Germany: Elbe-Auen (a) and Weiherbach (b). Areas in black represent data gaps. (Adapted from Hajnsek, I. et al., IEEE Trans. Geosci. Remote Sens., 41(4), 727, 2003, doi: 10.1109/tgrs.2003.810702.)

conditions such as cloud cover and haze. The number of SAR satellites in orbit continues to increase and the engineering behind these satellites has led to a greater diversity in SAR configurations. This means that users now have choices in incidence angle and polarization and, in some cases, access to polarimetric data (Table 8.4). Research has demonstrated that success in this application will be best achieved when data can be accessed at more than one frequency and polarization. The choice of incidence angle and polarization is clear with researchers agreeing that shallower angles and cross polarizations are best for roughness and residue mapping. The availability of polarimetriccapable sensors is relatively recent, and thus more research is needed to develop methods to exploit these complex data. The primary challenge is the coupling of roughness, soil moisture, and residue in the SAR response. This coupling complicates the extraction of tillage information from the signal but can be accomplished by exploiting SAR data acquired at multiple configurations (frequency, angle, or polarization). Planned, and recently launched, satellites include the C-band RADARSAT Constellation (Canada), C-band Sentinel-1A and B (ESA), and L-band SAOCOM-1A and B (Comisión Nacional de Actividades Espaciales (CONAE)) (Table 8.4). These satellites will provide frequent data at a range of angles and polarizations and promise to provide an important source of data for monitoring tillage.

\subsection{Review and o utlook}

This chapter has summarized recent progress to advance applications of remote-sensing technologies to broadscale assessment of tillage status. Nonetheless, important challenges remain. Here we recap some of the key elements of current research to apply remote-sensing technologies to broadscale, site-specific tillage assessment and then highlight some of the principal challenges this effort faces as further research progresses (see also Zheng et al. 2014).

Optical remote sensing and SAR data provide different capabilities for tillage assessment. Whereas optical remote-sensing imagery provides the spectral basis for detection of crop residues on soil surface, SAR data provide information on soil physical properties, such as roughness and texture, which can reveal the nature of tillage practices. With the presence of green vegetation, both SAR and optical remote-sensing data have difficulties to discriminate different tillage categories. Remotely sensed imagery sensitive to radiation near $2100 \mathrm{~nm}$ cellulose absorption bands provides the best opportunity to estimate crop residue cover and to map tillage practices. In this context, the best three tillage indices are CAI, SINDRI, and NDTI. Because current satellite hyperspectral systems cannot provide systematic spatial coverage, at present, multispectral imagery now forms the preferred 
candidate for a broadscale tillage assessment. Multitemporal imagery is required to provide accurate assessment on tillage practices for regions with diverse crop calendars-a range of dates for soil preparation and planting schedules. The upcoming launch of several new satellite systems with optical sensors will offer solid opportunities to enhance our ability to monitor rapid changes of agricultural lands, providing timely, and lowcost, information for monitoring site-specific tillage assessment.

\subsection{1 c hallenges-o ptical Systems}

As noted previously, optical systems provide capabilities for monitoring tillage in a systematic manner. Yet they are subject to disruptive influences of soil moisture variations and uneven terrain. Possible solutions include (1) development of terrain and soil data layers that can guide interpretations of image data in such areas and (2) development of specialized indices or other strategies to detect or adjust for spectral variations caused by these effects. Further, although current systems can provide revisit intervals adequate in key agricultural regions, these capabilities may not be adequate in other regions, where higher cloud cover may require more frequent revisit capabilities to acquire cloud-free coverage necessary for the temporal sequences required for the minNDTI strategy.

From evaluation of the SINDRI and CAI tillage indices, we know that carefully, and narrowly, defined spectral channels are effective in tillage assessment. However, it seems unlikely that future satellite systems are likely to incur the costs of designing and operating new bands to support a single application mission. As a result, future opportunities for optical tillage assessment seem likely to be based on the NDTI model (which relies upon broadly defined spectral channels, but ones that support a range of application missions), relying upon the sequential imagery to apply strategies, such as the minNDTI.

\subsection{2 c hallenges-SAR Systems}

Although specific strategies for application of SAR for monitoring tillage status are still under development, it has great potential for systematic tillage assessment, in part because of its ability to acquire data in the presence of cloud cover and the potential to extract a suit of terrain measurements as part of a tillage assessment mission. As reported here, current research has been successful in applying radar fundamentals to the tillage assessment task, although the multiplicity of system variables that interact with each other and with the landscape offers challenges in isolating tillage information. The SAR tillage effort has yet to scale current findings to examine larger regions, allowing identification of unexpected effects of local terrain, interactions between agricultural practices, and the geometries of varied SAR satellite systems.

\subsection{3 c hallenges-Sequential o bservations}

Monitoring tillage status by remote sensing by its nature requires broadscale observation of very large regions. Within such broad regions, weather, terrain, and local practices vary, necessarily dispersing tillage and planting data operations over intervals of several weeks. Because the tillage event is ephemeral, soon concealed by the foliage of the emerging crop, it must be assessed as it occurs, not at a later date. As a result, a single snapshot satellite image can capture only a partial record of a region's tillage pattern. This effect is significant regardless of the sensor system or tillage assessment strategy-sequential imagery of the entire planting season is necessary to observe the correct tillage status of a landscape. Otherwise, the inventory will record only a portion of the tillage operations within the area. In this context, both SAR and optical satellite systems are challenged to provide reliable coverage in the sense that current revisit intervals of optical systems are subject to disruption by cloud cover, and current SAR systems are challenged to simultaneously provide the spatial detail, broadscale coverage, and revisit intervals necessary to observe the full planting season.

\subsection{4 $\mathrm{c}$ hallenges-Global $\mathrm{t}$ illage Monitoring}

Current research to apply remote sensing to tillage assessment has been developed largely in midlatitudes, in regions characterized by large fields, simple crop calendars that apply for very large areas, limited numbers of crops, known crop rotation sequences, and availability of supporting data. These conditions may apply in many of the other major grain-producing regions (e.g., Brazil, China, Argentina, Ukraine, and Mexico), where current tillage assessment strategies may transfer. Many of the world's other agricultural regions present much different conditions that do not favor their direct transfer. For irrigated crops, there may be several planting cycles. Many tropical regions are characterized by smaller fields and complicated crop calendars, so investigators may require mastery of detailed knowledge of a diversity of cropping systems and irrigation practices, which may all vary within short distances. Such agricultural systems may exhibit levels of spatial and temporal variability that will greatly complicate applications of remote-sensing strategies that have been successful in the context of midlatitude agricultural systems.

\subsection{5 c hallenges-Field and Validation Data}

Further advances in tillage assessment will require development of additional strategies for collection of field data for preparation of assessment model and for valuation of survey findings. Field data collection campaigns following established and co-coordinated protocols have a role in broadscale survey, especially when it is feasible to mobilize a network or experienced volunteers to support campaigns. However, such efforts inevitably encounter logistical problems, especially when unfavorable weather creates uncertainties or prevents acquisition of viable imagery. Work to investigate alternative strategies, including the feasibility of using commercial satellite imagery to collect tillage observations to support model development and validation of project findings, deserves attention. 


\section{References}

Adams, J. R., A. A. Berg, H. McNairn, and A. Merzouki. 2013a. Sensitivity of C-band SAR polarimetric variables to unvegetated agricultural fi lds. Can. J. Remote Sens. 39 (1): 1-16. doi: $10.5589 / \mathrm{m} 13-003$.

Adams, J. R., T. L. Rowlandson, S. J. McKeown, A. A. Berg, H. McNairn, and S. J. Sweeney. 2013b. Evaluating the Cloude-Pottier and Freeman-Durden scattering decompositions for distinguishing between unharvested and post-harvest agricultural fi lds. Can. J. Remote Sens. 39 (4): 318-327. doi: 10.5589/m13-040.

Alberga, V., G. Satalino, and D. K. Staykova. 2008. Comparison of polarimetric SAR observables in terms of classifi ation performance. Int. J. Remote Sens. 29 (14): 4129-4150. doi: 10.1080/01431160701840182.

Asrar, G., R. B. Myneni, and E. T. Kanemasu. 1989. Estimation of plant-canopy attributes from spectral reflectance measurements. In Theory and Applications of Optical Remote Sensing, G. Asrar (ed.), pp. 252-296. New York: John Wiley.

Aubert, M., N. Baghdadi, M. Zribi, A. Douaoui, C. Loumagne, F. Baup, M. El Hajj, and S. Garrigues. 2011. Analysis of TerraSAR-X data sensitivity to bare soil moisture, roughness, composition and soil crust. Remote Sens. Environ. 115 (8): 1801-1810. doi: http://dx.doi.org/10.1016/j.rse.2011.02.021.

Baghdadi, N., I. Gherboudj, M. Zribi, M. Sahebi, C. King, and F. Bonn. 2004. Semi-empirical calibration of the IEM backscattering model using radar images and moisture and roughness fi ld measurements. Int. J. Remote Sens. 25 (18): 3593-3623. doi: 10.1080/01431160310001654392.

Baghdadi, N., N. Holah, and M. Zribi. 2006. Calibration of the integral equation model for SAR data in C-band and $\mathrm{HH}$ and VV polarizations. Int. J. Remote Sens. 27 (4): 805-816. doi: 10.1080/01431160500212278.

Baghdadi, N., M. Zribi, C. Loumagne, P. Ansart, and T. P. Anguela. 2008. Analysis of TerraSAR-X data and their sensitivity to soil surface parameters over bare agricultural fields. Remote Sens. Environ. 112 (12): 4370-4378. doi: 10.1016/j.rse.2008.08.004.

Baumgardner, M. F., L. F. Silva, L. L. Biehl, and E. R. Stoner. 1986. Reflectance properties of soils. In Advances in Agronomy, N. C. Brady (ed.), pp. 1-44. Academic Press, Orlando, FL.

Beaudoin, A., T. Le Toan, and Q. H. J. Gwyn. 1990. SAR observations and modeling of the $\mathrm{C}$-band backscatter variability due to multiscale geometry and soil moisture. IEEE Trans. Geosci. Remote Sens. 28 (5): 886-895. doi: 10.1109/36.58978.

Ben-Dor, E. 2002. Quantitative remote sensing of soil properties. Adv. Agron., 75:173-243.

Biard, F. and F. Baret. 1997. Crop residue estimation using multiband refl ctance. Remote Sens. Environ. 59 (3): 530-536.

Boisvert, J. B., Q. H. J. Gwyn, B. Brisco, D. Major, and R. J. Brown. 1995. Evaluation of soil moisture techniques and microwave penetration depth for radar applications. Can. J. Remote Sens. 21: $110-123$.
Booth, D. T., S. E. Cox, and R. D. Berryman. 2006. Point sampling digital imagery with 'SamplePoint'. Environ. Monit. Assess. 123: 97-108.

Bricklemyer, R. S., R. L. Lawrence, P. R. Miller, and N. Battogtokh. 2006. Predicting tillage practices and agricultural soil disturbance in north central Montana with Landsat imagery. Agric. Ecosyst. Environ. 114 (2-4): 210-216. doi: 10.1016/j. agee.2005.10.005.

Brisco, B., R. J. Brown, B. Snider, G. J. Sofko, J. A. Koehler, and A. G. Wacker. 1991. Tillage effects on the radar backscattering coeffici t of grain stubble fi lds. Int. J. Remote Sens. 12 (11): 2283-2298. doi: 10.1080/01431169108955258.

Brown, D. J., K. D. Shepherd, M. G. Walsh, M. Dewayne Mays, and T. G. Reinsch. 2006. Global soil characterization with VNIR diffuse refl ctance spectroscopy. Geoderma 132 (3-4): 273-290. doi: 10.1016/j.geoderma.2005.04.025.

Clark, R. N., G. A. Swayze, R. Wise, K. E. Livo, T. M. Hoefen, R. F. Kokaly, and S. J. Sutley. 2007. USGS digital spectral library splib06a. Available online at: http://speclab.cr.usgs. gov/spectral.lib06/ (Accessed January 11, 2013).

Cloude, S. R. and E. Pottier. 1997. An entropy based classification scheme for land applications of polarimetric SAR. IEEE Trans. Geosci. Remote Sens. 35 (1): 68-78. doi: $10.1109 / 36.551935$.

Corak, S. J., T. C. Kaspar, and D. W. Meek. 1993. Evaluating methods for measuring residue cover. J. Soil Water Conserv. 48: 700-704.

CTIC. 2014. National crop residue management survey. http://www.ctic.purdue.edu/CRM/ (accessed January 21, 2014).

DigitalGlobe, 2014. Content collection. Available online at: https://www.digitalglobe.com/about-us/content-collection \#satellites\&worldview-3. (Accessed April 8, 2015).

Daughtry, C. S. T. 2001. Discriminating crop residues from soil by shortwave infrared refl ctance. Agron. J. 93 (1): 125-131.

Daughtry, C. S. T., P. C. Doraiswamy, E. R. Hunt, Jr., A. J. Stern, J. E. McMurtrey, III, and J. H. Prueger. 2006. Remote sensing of crop residue cover and soil tillage intensity. Soil Tillage Res. 91 (1-2): 101-108.

Daughtry, C. S. T. and E. R. Hunt, Jr. 2008. Mitigating the effects of soil and residue water contents on remotely sensed estimates of crop residue cover. Remote Sens. Environ. 112 (4): 1647-1657. doi: 10.1016/j.rse.2007.08.006.

Daughtry, C. S. T., E. R. Hunt, Jr., P. C. Doraiswamy, and J. E. McMurtrey, III. 2005. Remote sensing the spatial distribution of crop residues. Agron. J. 97 (3): 864-871. doi: 10.2134/agronj2003.0291.

Daughtry, C. S. T., E. R. Hunt, Jr., and J. E. McMurtrey, III. 2004. Assessing crop residue cover using shortwave infrared refl ctance. Remote Sens. Environ. 90 (1): 126-134. doi: 10.1016/j.rse.2003.10.023.

Daughtry, C. S. T., G. Serbin, J. B. Reeves, III, P. C. Doraiswamy, and E. R. Hunt, Jr. 2010. Spectral refl ctance of wheat residue during decomposition and remotely sensed estimates of residue cover. Remote Sens. 2 (2): 416-431. 
de Matthaeis, P., P. Ferrazzoli, G. Schiavon, and D. Solimini. 1991. Radar response to vegetation parameters: Comparison between theory and MAESTRO-1 results. Paper presented at the Proceedings of the International Geoscience and Remote Sensing Symposium (IGARSS 1991), Espoo, Finland.

de Matthaeis, P., P. Ferrazzoli, G. Schiavon, and D. Solimini. 1992. Agriscatt and MAESTRO: Multifrequency radar experiments for vegetation remote sensing. Paper presented at the MAESTRO-1/AGRISCATT: Radar Techniques for Forestry and Agricultural Applications, Final Workshop, Noordwijk, the Netherlands.

Dubois, P. C., J. Van Zyl, and T. Engman. 1995. Measuring soil moisture with imaging radars. IEEE Trans. Geosci. Remote Sens. 33 (4): 915-926. doi: 10.1109/36.406677.

Evans, D. L., T. G. Farr, J. J. van Zyl, and H. A. Zebker. 1988. Radar polarimetry: Analysis tools and applications. IEEE Trans. Geosci. Remote Sens. 26 (6): 774-788. doi: 10.1109/36.7708.

Evans, D. L. and M. O. Smith. 1991. Separation of vegetation and rock signatures in thematic mapper and polarimetric SAR images. Remote Sens. Environ. 37 (1): 63-75. doi: 10.1016/0034-4257(91)90051-7.

Faulkner, E. H. 1943. Plowman's Folly. New York: Grosset \& Dunlap.

Feng, G., Masek, J., Schwaller, M., and Hall, F. 2006. On the blending of the Landsat and MODIS surface refl ctance: Predicting daily Landsat surface refl ctance. Geoscience and Remote Sensing, IEEE Transactions on, 44 (8), 2207-2218.

Freeman, A. and S. L. Durden. 1998. A three-component scattering model for polarimetric SAR data. IEEE Trans. Geosci. Remote Sens. 36 (3): 963-973. doi: 10.1109/36.673687.

Fung, A. K., Z. Li, and K. S. Chen. 1992. Backscattering from a randomly rough dielectric surface. IEEE Trans. Geosci. Remote Sens. 30 (2): 356-368. doi: 10.1109/36.134085.

Galloza, M. S., M. M. Crawford, and G. C. Heathman. 2013. Crop residue modeling and mapping using landsat, ALI, hyperion and airborne remote sensing data. IEEE J. Sel. Topics Appl. Earth Observ. 6 (2): 446-456. doi: 10.1109/ jstars.2012.2222355.

Gao, F., J. Masek, M. Schwaller, and F. Hall. 2006. On the Blending of the Landsat and MODIS Surface refl ctance: Predict daily landsat surface refl ctance, IEEE Transactions on Geoscience and Remote Sensing, 44 (8): 2207-2218.

Gausman, H. W., Gerbermann, A. H., Wiegand, C. L., Leamer, R. W., Rodriguez, R. R., and Noriega, J. R. (1975). Reflectance differences between crop residues and bare soils. Soil Sci. Soc. Am. J. 39 (4): 752-755.

Gowda, P. H., B. J. Dalzell, D. J. Mulla, and F. Kollman. 2001. Mapping tillage practices with landstat thematic mapper based logistic regression models. J. Soil Water Conserv. 56 (2): 91-96.

Hadria, R., B. Duchemin, F. Baup, T. Le Toan, A. Bouvet, G. Dedieu, and M. Le Page. 2009. Combined use of optical and radar satellite data for the detection of tillage and irrigation operations: Case study in Central Morocco. Agric. Water Manage. 96 (7): 1120-1127. doi: 10.1016/j.agwat.2009.02.010.
Hajnsek, I., E. Pottier, and S. R. Cloude. 2003. Inversion of surface parameters from polarimetric SAR. IEEE Trans. Geosci. Remote Sens. 41 (4): 727-744. doi: 10.1109/tgrs.2003.810702.

Hasted, J. B. 1973. Aqueous Dielectrics. London, U.K.: Chapman \& Hall.

Henderson, T. L., M. F. Baumgardner, D. P. Franzmeier, D. E. Stott, and D. C. Coster. 1992. High dimensional refl ctance analysis of soil organic matter. Soil Sci. Soc. Am. J. 56 (3): 865-872. doi: 10.2136/sssaj1992.03615995005600030031x.

Hunt, Jr., E. R. 1989. Detection of changes in leaf water content using near- and middle-infrared refl ctances. Remote Sens. Environ. 30 (1): 43-54. doi: 10.1016/0034-4257(89)90046-1.

Irons, J. R., R. A. Weismiller, and G. W. Petersen. 1989. Soil refl ctance. In Theory and Applications of Optical Remote Sensing, G. Asrar (ed.). New York: John Wiley \& Sons, pp. 66-106.

Jackson, T. J., H. McNairn, M. A. Weltz, B. Brisco, and R. Brown. 1997. First order surface roughness correction of active microwave observations for estimating soil moisture. IEEE Trans. Geosci. Remote Sens. 35 (4): 1065-1068. doi: 10.1109/36.602548.

Jackson, T. J. and P. E. O'Neill. 1991. Microwave emission and crop residues. Remote Sens. Environ. 36 (2): 129-136. doi: 10.1016/0034-4257(91)90035-5.

Karlen, D. L., N. C. Wollenhaupt, D. C. Erbach, E. C. Berry, J. B. Swan, N. S. Eash, and J. L. Jordahl. 1994. Long-term tillage effects on soil quality. Soil Tillage Res. 32 (4): 313-327. doi:10.1016/0167-1987(94)00427-G.

Laflen, J. M., M. Amemiya, and E. A. Hintz. 1981. Measuring crop residue cover. J. Soil Water Conserv. 36 (6): 341-343.

Lal, R. 2004. Soil carbon sequestration to mitigate climate change. Geoderma 123 (1-2): 1-22. doi:10.1016/j.geoderma.2004. 01.032 .

Lal, R., J. M. Kimble, R. F. Follett, and C. V. Cole. 1998. The Potential of U.S. Cropland to Sequester Carbon and Mitigate the Greenhouse Effect. Boca Raton, FL: Lewis Publishers.

Langman, A. and M. R. Inggs. 1994. The use of polarimetry in subsurface radar. Paper presented at the Proceedings in International Geoscience and Remote Sensing Symposium, 1994 (IGARSS '94). Surface and Atmospheric Remote Sensing: Technologies, Data Analysis and Interpretation, August 8-12, 1994.

Lee, J. S. and E. Pottier. 2009. Polarimetric Radar Imaging: From Basics to Applications. New York: CRC Press.

Lewis, A. J. and F. M. Henderson. 1998. Radar fundamentals: The geoscience perspective. In Principles and Applications of Imaging Radar. Manual of Remote Sensing, F. M. Henderson and A. J. Lewis (eds.). New York: John Wiley \& Sons, pp. 131-181.

Li, Y., T. Liu, G. Lampropoulos, H. McNairn, J. Shang, and R. Touzi. 2014. RADARSAT-2 POLInSAR coherence optimization for agriculture crop change detection. Paper presented at the Proceedings in International Geoscience and Remote Sensing Symposium (IGARSS 2014), Quebec City, Quebec, Canada.

McNairn, H., J. B. Boisvert, D. J. Major, Q. H. J. Gwyn, R. J. Brown, and A. M. Smith. 1996. Identifi ation of agricultural tillage practices from C-band radar backscatter. Can. J. Remote Sens. 22: 154-162. 
McNairn, H. and B. Brisco. 2004. The application of C-band polarimetric SAR for agriculture: A review. Can. J. Remote Sens. 30 (3): 525-542. doi: 10.5589/m03-068.

McNairn, H., C. Duguay, J. Boisvert, E. Huffman, and B. Brisco. 2001. Defini g the sensitivity of multi-frequency and multipolarized radar backscatter to post-harvest crop residue. Can. J. Remote Sens. 27 (3): 247-263.

McNairn, H., C. Duguay, B. Brisco, and T. J. Pultz. 2002. The effect of soil and crop residue characteristics on polarimetric radar response. Remote Sens. Environ. 80 (2): 308-320. doi: 10.1016/s0034-4257(01)00312-1.

McNairn, H. and R. Protz. 1993. Mapping corn residue cover on agricultural fi lds in Oxford County, Ontario, using Thematic Mapper. Can. J. Remote Sens. 19: 152-158.

McNairn, H., D. Wood, Q. H. J. Gwyn, and R. J. Brown. 1998. Mapping tillage and crop residue management practices with RADARSAT. Can. J. Remote Sens. 24: 28-35.

Merzouki, A., H. McNairn, and A. Pacheco. 2010. Evaluation of the Dubois, Oh, and IEM radar backscatter models over agricultural fields using C-band RADARSAT-2 SAR image data. Can. J. Remote Sens. 36 (S2): S274-S286. doi: 10.5589/ m10-055.

Merzouki, A., H. McNairn, and A. Pacheco. 2011. Mapping soil moisture using RADARSAT-2 data and local autocorrelation statistics. IEEE J. Sel. Topics Appl. Earth Observ. 4 (1): $1-10$.

Milisavljević, N., D. Closson, and I. Bloch. 2010. Detecting human-induced scene changes using coherent change detection in SAR images. Paper presented at the ISPRS TC VII Symposium-100 Years ISPRS, Vienna, Austria, July 5-7.

Morrison, J. E., C.-H. Huang, D. T. Lightle, and C. S. T. Daughtry. 1993. Residue measurement techniques. J. Soil Water Conserv. 48 (6): 478-483.

Nagler, P. L., C. S. T. Daughtry, and S. N. Goward. 2000. Plant litter and soil refl ctance. Remote Sens. Environ. 71 (2): 207215. doi:10.1016/S0034-4257(99)00082-6.

NASA/JPL. 2008. ASTER user advisory. http://asterweb.jpl.nasa. gov/swir-alert.asp (accessed January 15, 2014).

Oh, Y. 2004. Quantitative retrieval of soil moisture content and surface roughness from multipolarized radar observations of bare soil surfaces. IEEE Trans. Geosci. Remote Sens. 42 (3): 596-601. doi: 10.1109/tgrs.2003.821065.

Oh, Y., K. Sarabandi, and F. T. Ulaby. 1992. An empirical model and an inversion technique for radar scattering from bare soil surfaces. IEEE Trans. Geosci. Remote Sens. 30 (2): 370381. doi: 10.1109/36.134086.

Pacheco, A. and H. McNairn. 2010. Evaluating multispectral remote sensing and spectral unmixing analysis for crop residue mapping. Remote Sens. Environ. 114 (10): 2219-2228. doi:10.1016/j.rse.2010.04.024.

Pacheco, A. M., H. McNairn, and A. Merzouki. 2010. Evaluating TerraSAR-X for the identifi ation of tillage occurrence over an agricultural area in Canada. Proc. SPIE 7824, Remote Sensing for Agriculture, Ecosystems, and Hydrology XII, 78240P. doi: 10.1117/12.868218.
Panciera, R., F. MacGill, M. Tanase, K. Lowell, and J. Walker. 2013. Sensitivity of TerraSAR-X-band data to surface parameters in bare agricultural areas. Paper presented at the IEEE 2013 International Geoscience and Remote Sensing Symposium (IGARSS), July 21-26, 2013.

Rahman, M. M., M. S. Moran, D. P. Thoma, R. Bryant, C. D. Holifi ld Collins, T. Jackson, B. J. Orr, and M. Tischler. 2008. Mapping surface roughness and soil moisture using multiangle radar imagery without ancillary data. Remote Sens. Environ. 112 (2): 391-402. doi:10.1016/j.rse.2006.10.026.

Rouse, J. W., Jr., R. H. Haas, J. A. Schell, and D. W. Deering. 1973. Monitoring the vernal advancement and retrogradation (green wave effect) of natural vegetation. Prog. Rep. RSC 1978-1, Remote Sensing Center, Texas A\&M Univ., College Station, 93p. (NTIS No. E73-106393).

Sabins, F. F. 1986. Remote Sensing: Principles and Interpretation. San Francisco, CA: Freeman Publishers.

Samui, P., P. H. Gowda, T. Oommen, T. A. Howell, T. H. Marek, and D. O. Porter. 2012. Statistical learning algorithms for identifying contrasting tillage practices with Landsat Thematic Mapper data. Int. J. Remote Sens. 33 (18): 5732-5745. doi: 10.1080/01431161.2012.671555.

Serbin, G., C. S. T. Daughtry, E. R. Hunt, Jr., D. J. Brown, and G. W. McCarty. 2009a. Effect of soil spectral properties on remote sensing of crop residue cover. Soil Sci. Soc. Am. J. 73 (5): 1545-1558. doi: 10.2136/sssaj2008.0311.

Serbin, G., C. S. T. Daughtry, E. R. Hunt, Jr., J. B. Reeves III, and D. J. Brown. 2009b. Effects of soil composition and mineralogy on remote sensing of crop residue cover. Remote Sens. Environ. 113 (1): 224-238.

Serbin, G., E. R. Hunt, Jr., C. S. T. Daughtry, G. W. McCarty, and P. C. Doraiswamy. 2009c. An improved ASTER index for remote sensing of crop residue. Remote Sens. 1 (4): 971-991.

Serbin, G., E. R. Hunt, Jr., C. S. T. Daughtry, and G. W. McCarty. 2013. Assessment of spectral indices for cover estimation of senescent vegetation. Remote Sens. Lett. 4 (6): 552-560. doi: 10.1080/2150704x.2013.767479.

Shelton, D. P., R. Kanable, and P. L. Jasa. 1993. Estimating percent residue cover using the line-transect method. http://www.ianrpubs.unl.edu/live/g1931/build/g1931.pdf (assessed February 5, 2014).

Slaton, M. R., E. R. Hunt, Jr., and W. K. Smith. 2001. Estimating near-infrared leaf refl ctance from leaf structural characteristics. Am. J. Bot. 88 (2): 278-284. doi: 10.2307/2657018.

Sokol, J., H. NcNairn, and T. J. Pultz. 2004. Case studies demonstrating the hydrological applications of C-band multipolarized and polarimetric SAR. Can. J. Remote Sens. 30 (3): 470-483. doi: 10.5589/m03-073.

South, S., J. Qi, and D. P. Lusch. 2004. Optimal classifi ation methods for mapping agricultural tillage practices. Remote Sens. Environ. 91 (1): 90-97. doi: 10.1016/j.rse.2004.03.001.

Stoner, E. R. and M. F. Baumgardner. 1981. Characteristic variations in reflectance of surface soils. Soil Sci. Soc. Am. J. 45 (6): 1161-1165. doi: 10.2136/sssaj1981.03615995004500060031x. 
Stoner, E. R., M. F. Baumgardner, R. A. Weismiller, L. L. Biehl, and B. F. Robinson. 1980. Extension of laboratory-measured soil spectra to fi ld conditions. Soil Sci. Soc. Am. J. 44 (3): 572574. doi: 10.2136/sssaj1980.03615995004400030028x.

Streck, N. A., D. Rundquist, and J. Connot. 2002. Estimating residueal wheat dry matter from remote sensing measurements. Photogramm. Eng. Remote Sens. 68: 1193-1201.

Sudheer, K. P., P. Gowda, I. Chaubey, and T. Howell. 2010. Artific al neural network approach for mapping contrasting tillage practices. Remote Sens. 2 (2): 579-590.

Thoma, D. P., S. C. Gupta, and M. E. Bauer. 2004. Evaluation of optical remote sensing models for crop residue cover assessment. J. Soil Water Conserv. 59 (5): 224-233.

Thomas, J. R. and H. W. Gausman. 1977. Leaf refl ctance vs. leaf chlorophyll and carotenoid concentrations for eight crops. Agron. J. 69 (5): 799-802. doi: 10.2134/agronj1977.0002196 $2006900050017 \mathrm{x}$.

Touzi, R., S. Goze, T. Le Toan, A. Lopes, and E. Mougin. 1992. Polarimetric discriminators for SAR images. IEEE Trans. Geosci. Remote Sens. 30 (5): 973-980. doi: 10.1109/36.175332.

Ulaby, F. T., D. Held, M. C. Donson, K. C. McDonald, and T. B. A. Senior. 1987. Relating polaization phase difference of SAR signals to scene properties. IEEE Trans. Geosci. Remote Sens. GE-25 (1): 83-92. doi: 10.1109/tgrs.1987.289784.

Ulaby, F. T., R. K. Moore, and A. K. Fung. 1986. Microwave Remote Sensing: Active and Passive, Vol. III. Reading, MA: Addison-Wesley.

USDA-NRCS. 2014 The soil tillage intensity rating (STIR). Available on-line at: http://www.nrcs.usda.gov/Internet/FSE_ DOCUMENTS/stelprdb1119754.pdf (accessed February 28, 2014).

van Deventer, A. P., A. D. Ward, P. H. Gowda, and J. G. Lyon. 1997. Using thematic mapper data to identify contrasting soil plains and tillage practices. Photogramm. Eng. Remote Sens. 63 (1): 87-93.

van Zyl, J. J. 1989. Unsupervised classifi ation of scattering behavior using radar polarimetry data. IEEE Trans. Geosci. Remote Sens. 27 (1): 36-45. doi: 10.1109/36.20273.

Wander, M. M. and L. E. Drinkwater. 2000. Fostering soil stewardship through soil quality assessment. Appl. Soil Ecol. 15 (1): 61-73. doi: 10.1016/S0929-1393(00)00072-X.
Watts, J. D., R. L. Lawrence, P. R. Miller, and C. Montagne. 2009. Monitoring of cropland practices for carbon sequestration purposes in north central Montana by Landsat remote sensing. Remote Sens. Environ. 113 (9): 1843-1852. doi: 10.1016/j.rse.2009.04.015.

Watts, J. D., S. L. Powell, R. L. Lawrence, and T. Hilker. 2011. Improved classification of conservation tillage adoption using high temporal and synthetic satellite imagery. Remote Sens. Environ. 115 (1): 66-75. doi: 10.1016/j. rse.2010.08.005.

West, T. O. and G. Marland. 2002. A synthesis of carbon sequestration, carbon emissions, and net carbon flux in agriculture: Comparing tillage practices in the United States. Agric. Ecosyst. Environ. 91 (1-3): 217-232. doi: 10.1016/ S0167-8809(01)00233-X.

Workman, J. J. and L. Weyer. 2008. Practical Guide to Interpretive Near-Infrared Spectroscopy. Boca Raton, FL: Taylor \& Francis Group.

Yilmaz, M. T., E. R. Hunt, Jr., and T. J. Jackson. 2008. Remote sensing of vegetation water content from equivalent water thickness using satellite imagery. Remote Sens. Environ. 112 (5): 2514-2522. doi: 10.1016/j.rse.2007.11.014.

Zheng, B., J. B. Campbell, and K. M. de Beurs. 2012. Remote sensing of crop residue cover using multi-temporal Landsat imagery. Remote Sens. Environ. 117 (0): 177-183. doi: 10.1016/j.rse.2011.08.016.

Zheng, B., J. B. Campbell, G. Serbin, and C. S. T. Daughtry. 2013 a. Multi-temporal remote sensing of crop residue cover and tillage practices: A validation of the minNDTI strategy in the United States. J. Soil Water Conserv. 68 (2): 120-131.

Zheng, B., J. B. Campbell, G. Serbin, and J. M. Galbraith. 2014. Remote sensing of crop residue and tillage practices: Present capabilities and future prospects. Soil Tillage Res. 138 (0): 26-34. doi: 10.1016/j.still.2013.12.008.

Zheng, B., J. B. Campbell, Y. Shao, and R. H. Wynne. 2013b. Broad-scale monitoring of tillage practices using sequential landsat imagery. Soil Sci. Soc. Am. J. 77 (5): 1755-1764. doi: 10.2136/sssaj2013.03.0108.

Zhu, X., J. Chen, F. Gao, X. Chen, and J. G. Masek. 2010. An enhanced spatial and temporal adaptive reflectance fusion model for complex heterogeneous regions. Remote Sens. Environ. 114 (11):2610-2623. doi: 10.1016/j.rse.2010.05.032. 